\title{
CERÁMICA DE BARNIZ NEGRO EN LA ANTIGUA CAURA
}

\section{BLACK-GLAZED WARE IN ANCIENT CAURA}

\author{
JOSÉ LUIS ESCACENA CARRASCO* \\ MARÍA TERESA HENARES GUERRA** \\ JUAN JOSÉ VENTURA MARTÍNEZ***
}

\begin{abstract}
Resumen: En este artículo presentamos el primer estudio realizado sobre cerámica fina de barniz negro procedente de la antigua Caura (Coria del Río, Sevilla, España). La cronología de los materiales abarca un período comprendido entre la segunda mitad del siglo $\mathrm{V}$ y el siglo I a.C. Se estudian tanto las importaciones procedentes de Grecia (Ática) e Italia (Campania, Toscana, entorno de Nápoles y Sicilia) como los productos del Mediterráneo occidental.

Palabras clave: Cerámica fina de barniz negro. Cerámica ática. Cerámicas campanienses.
\end{abstract}

\section{INTRODUCCIÓN}

La ciudad de Caura nació en el Cerro de San Juan, ubicado en el centro histórico de la actual Coria del Río, en la provincia de Sevilla (fig. 1). Este cabezo está formado hoy por una pequeña meseta terciaria coronada por una acumulación de estratos antrópicos. En conjunto, presenta en la actualidad casi $27 \mathrm{~m}$ s.n.m. La superposición de capas arqueológicas prehistóricas y antiguas es producto de varios miles de años de una

\footnotetext{
* Departamento de Prehistoria y Arqueología. Universidad de Sevilla. Correo-e: escacena@us.es

** Arqueóloga profesional. Correo-e: maytehenares@gmail.com

*** Instituto del Patrimonio de Archidona (Málaga). Correo-e: museo@archidona.es
}

\begin{abstract}
We present in this paper the very first study on black-glazed fine ware from the ancient Caura (Coria Del Río, Seville, Spain). The research object materials chronology goes from the second half of the Vth century to Ist century BC. We analyze the imported wares from Greece (Attica) and Italy (Campania, Tuscany, Naples hinterland and Sicily), and also the western Mediterranean ones.
\end{abstract}

Key words: Black-glazed fine wares. Attican wares. Campanian wares.

ocupación humana que se inicia al menos en la Edad del Cobre y que, con algún posible hiato, llega hasta época medieval. El promontorio contiene, pues, parte de la documentación básica de la Caura turdetana y romana, momento al que pertenece el material cerámico aquí estudiado. Para esta época, el depósito previo de una importante estratigrafía de origen humano sobre el sustrato geológico proporcionaba al sitio una amplia visibilidad sobre el entorno inmediato, y especialmente sobre la llanura aluvial del Guadalquivir (Keay et al. 2001: 403). En el horizonte oriental que se divisa desde este otero sería fácilmente visible la ciudad de Orippo, hoy en término de Dos Hermanas y entonces también a orillas del estuario bético.

Los datos aquí analizados se obtuvieron en la década de los noventa del siglo pasado gracias a un 
proyecto general de investigaciones arqueológicas, aprobado y subvencionado por la Consejería de Cultura de la Junta de Andalucía, que tenía como objetivo el análisis de la implantación humana en la paleodesembocadura del Guadalquivir y el establecimiento de la secuencia cultural holocénica de la zona. Dichas intervenciones consistieron en prospecciones superficiales en los términos municipales de Dos Hermanas, Coria del Río y La Puebla del Río (Escacena et al. 1997), así como en la realización de un sondeo estratigráfico en el mencionado Cerro de San Juan. En este sitio se pretendía obtener una lectura diacrónica de su ocupación, lo que se logró en dos campañas de excavación llevadas a cabo en 1994 y 1996 respectivamente (Escacena e Izquierdo 1999). A estas actividades del Proyecto Estuario se sumaron, a lo largo del desarrollo de las tareas planificadas con antelación, intervenciones preventivas en la propia Caura y en el cercano Cerro de la Albina. En las primeras se documentó un barrio fenicio dado a conocer extensamente en diversos trabajos (Escacena e Izquierdo 2001; Escacena 2002). Las segundas permitieron localizar una industria metalúrgica cercana a Caura y dependiente de esta ciudad. Allí se copelaba plata en época tartésica para su posterior introducción en las rutas del comercio oriental (Escacena y Henares 1999; Escacena et al. 2010).

El sondeo estratigráfico practicado en Caura (CorteA) proporcionó una gran cantidad de información sobre el asentamiento prehistórico y sobre la ciudad prerromana. Aunque parte de la documentación se encuentra aún en estudio, se ha llevado a cabo ya el análisis de la cerámica pintada turdetana (Coto 2011: 298-301) y de la vajilla de tipo Kuass (Escacena y Moreno 2014). Igualmente, las numerosas ánforas presentes en los distintos estratos de esta fase han permitido establecer las principales relaciones económicas del asentamiento con otras áreas del Guadalquivir y con diversos contextos prerromanos del ámbito mediterráneo (Ferrer et al. 2010).

Las intervenciones del Proyecto Estuario en Caura han proporcionado una buena cantidad de cerámica de barniz negro, con distintas variedades que se fechan básicamente a lo largo de la segunda mitad del I milenio a.C. Aparte de la importancia que estos materiales poseen por sí mismos para estudiar las relaciones económicas que el mundo turdetano estableció con otras zonas del Mediterráneo, hay que recordar que la presencia de vasos de tipología griega en este ámbito meridional de la península ibérica constituyó el modelo formal para el nacimiento de unos recipientes de tanta personalidad como los que se conocen con el apelativo genérico de cerámica de Kuass.
La cerámica de barniz negro hallada hasta la fecha en Caura se limita a contextos de hábitat. Carecemos por completo de testimonios localizados en ambientes funerarios. Esta situación no es un rasgo particular de dicho enclave, sino una característica general de Andalucía occidental. Entre otras posibles razones, este hecho puede deberse a la ausencia en el Bajo Guadalquivir y zonas aledañas, es decir, en el territorio nuclear turdetano, de necrópolis como las que originaba en las mismas fechas el mundo ibérico de la Alta Andalucía, del Sureste o del Levante español. Desconocemos qué hacían los Turdetanos con sus difuntos, pero parece evidente que no los depositaban bajo tierra, lo que explica esta falta generalizada de cementerios (Belén y Escacena 1992; Escacena y Belén 1994). En este aspecto, la Caura prerromana es un simple caso más de dicho patrón de conducta.

\section{CAURA: EL ASENTAMIENTO Y LA INTERVENCIÓN ARQUEOLÓGICA}

En los comienzos del I milenio a.C., la desembocadura del Guadalquivir se encontraba en las proximidades de las actuales poblaciones sevillanas de Coria y La Puebla del Río. La arteria fluvial conectaba en este punto con la ensenada bética, un golfo que ocupaba la actual comarca de Las Marismas. Este paleopaisaje ha sido confirmado por diversos estudios geoarqueológicos (Menanteau 1992; Arteaga et al. 1995), que han seguido recientemente a otros análisis de carácter geológico de mediados del siglo XX (Gavala 1959). Las reconstrucciones hipotéticas del entorno de Caura permiten sospechar que, al menos en época tartésica, el lugar contó con una zona portuaria privilegiada junto a la desembocadura del Guadalquivir, en una pequeña ensenada que formaría el río Pudio antes de convertirse, como es hoy, en afluente de aquel por la derecha. En cualquier caso, se desconocen los pormenores geográficos de los momentos en que se está desarrollando el mundo púnico gaditano y la primera dominación romana, etapas en que se constatan en la ciudad los testimonios aquí estudiados. Análisis geoarqueológicos muy recientes proponen que, en el primer milenio a.C., entre Caura y Nabrissa se extendía ya una amplia llanura mareal (Borja 2013: 103). En la pleamar, este principio de delta interior se cubría de una lámina de agua que originaba un golfo más expedito, pero en bajamar y en momentos de estiaje serían apreciables diversos brazos del río, esteros e islotes.

El topónimo Caura pertenece al tronco indoeuropeo, y significaría algo así como prominencia o lugar 


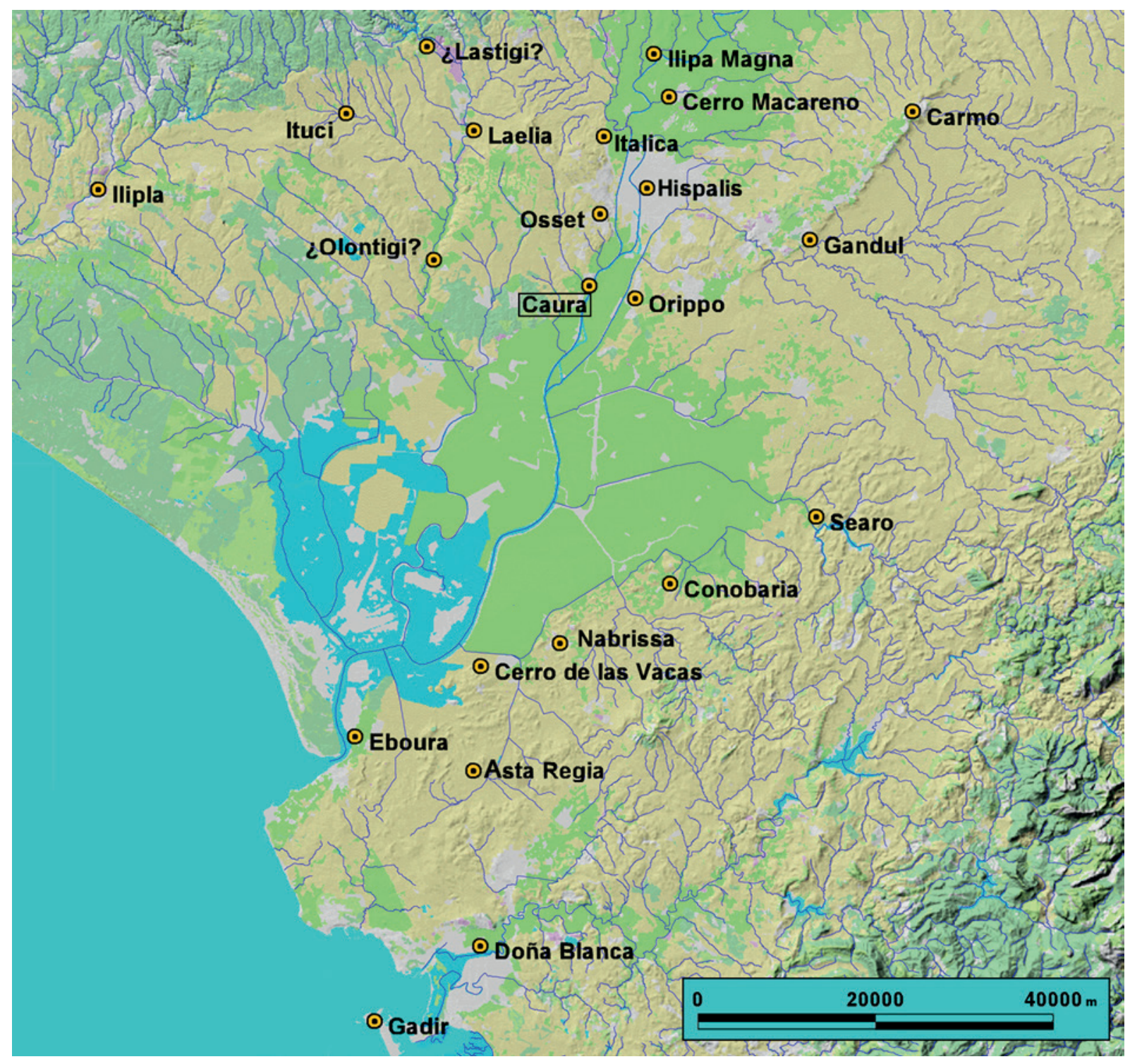

Figura 1. Caura en el contexto de las ciudades prerromanas de Andalucía occidental.

alto, ya que se relaciona con una vieja raíz verbal usada para la acción de "hinchar" (Padilla 1993). De ser correcta esta etimología, es probable que la ciudad adquiriera dicho nombre desde su fundación en tiempos tartésicos. De hecho, aunque en la fase prehistórica de la estratigrafía puede haber discontinuidad, no existe desocupación alguna del cabezo entre el siglo IX a.C. y los tiempos romanos, cuando está atestiguada la voz Caura a través de las monedas de su ceca y de una referencia de Plinio (Nat. Hist. 3, 11). Este autor alude a la población al citar diversos oppida de las orillas del Guadalquivir emplazados aguas abajo de Hispalis
(Sevilla). A comienzos del primer milenio a.C. el Cerro de San Juan contaba ya con más altura que otras elevaciones cercanas gracias a los estratos prehistóricos acumulados en el III y II milenios a.C. Es razonable, por tanto, que se le designara con un topónimo que destacaba precisamente este rasgo diferencial. Diversos análisis históricos identifican esta elevación con el Mons Cassius de la Ora Maritima (259-261). Dicha hipótesis, propuesta por M. Belén (1993: 49), ha quedado reforzada por el hallazgo de un templo fenicio (Escacena e Izquierdo 2000; 2008: 434-440). Los análisis arqueológicos muestran que este enclave turdetano mantuvo 
estrechas relaciones comerciales con el mundo púnico en general y con el gaditano en particular (Ferrer et al. 2010: 80).

El sondeo que ha proporcionado la cerámica aquí estudiada consistió en la apertura de un corte rectangular, de $10 \times 6 \mathrm{~m}$, acomodado al espacio vacío que dejó junto al flanco oriental del cabezo una de las construcciones hoy existentes, en concreto el Instituto de Educación Secundaria -IES- Caura (fig. 2). La extensión inicial fue reduciéndose conforme profundizaban los trabajos, en parte por motivos presupuestarios pero también por no desmontar las construcciones localizadas. La excavación se llevó a cabo mediante el levantamiento de estratos (en adelante, E), respetando siempre los límites sedimentarios de éstos y su conformación. Aun así, algunos de estos paquetes se subdividieron en niveles artificiales (en adelante, N) para poder detectar una posible evolución de su contenido arqueológico imperceptible en la expresión sedimentaria. Debido a la reducción de la superficie intervenida conforme aumenta la profundidad del sondeo, los paquetes estratigráficos más conocidos son los superiores, parte de los cuales contenían la cerámica de barniz negro. En cualquier caso, no todos estos estratos son de época antigua. Algunos los originaron obras realizadas en los años sesenta del siglo XX, especialmente las emprendidas en 1965 para la construcción de edificios docentes. Dichos condicionantes matizan el estudio del material arqueológico, que no cuenta en muchos casos con contextos primarios (fig. 3).

Los fragmentos de vasos de barniz negro hallados en un contexto estratigráfico más viejo proceden de EXIV, en concreto de su nivel más bajo (N-36). E-XIV es un estrato decantado con cierta rapidez, lo que se deduce de su homogeneidad estratigráfica a pesar de su grosor en origen $(c 1 \mathrm{~m})$. Tal uniformidad quedó reflejada a lo largo de toda su potencia tanto en el color castaño rojizo- como en la densidad, textura y grado de humedad; también en el reparto más o menos equilibrado de restos arqueológicos. La celeridad de su sedimentación la sugiere igualmente la posición vertical y/o inclinada de algunos trozos de adobes, hecho que extrañaría en una acumulación lenta. E-XIV contenía algunos fragmentos de ladrillos, de tegulae y de imbrices, materiales constructivos romanos no anteriores, en la Bética, al siglo I a.C. Esta cronología viene reforzada en este mismo estrato por terra sigillata Drag. 24 y Drag. 27, siempre posterior al cambio de Era.

En una gran zanja longitudinal, abierta en E-XIV con la probable intención de drenar las casas vecinas mediante el rebaje de la calle, se decantaron posteriormente
E-XV y XVI (por este orden). Se trata en ambos casos de rellenos relativamente lentos acumulados en una zona de paso, o área externa, necesariamente posterior a E-XIV según la estratigrafía. Para evitar la formación de lodo, en este sector se esparcía de vez en cuando gravilla suelta, una acción bien detectada en E-XVI. Estos áridos aparecen en ocasiones como cápsulas lenticulares de pequeños guijarros de cuarcita. Se trata de una técnica registrada en muchos asentamientos antiguos, casi siempre para consolidar suelos ubicados en espacios al aire libre. La costumbre cuenta con ejemplos cercanos en Laelia (Caballos et al. 2005: 91), en Setefilla (Aubet et al. 1983: 36) y en Hispalis (Jiménez 2002: 134), entre otros puntos. Dicha práctica estaba ampliamente extendida por los enclaves protohistóricos de la península ibérica, y se considera una introducción de costumbres fenicias en Occidente (Díes 2001: 87). En Caura, la gravilla, los múltiples fragmentos de cerámica y los restos faunísticos, principalmente trozos de huesos, compactaban el suelo y le daban dureza, facilitando así el tránsito de personas y animales. La hipótesis de que estemos ante una zona de paso se infiere, además, del alto grado de fragmentación y rodamiento de tales residuos (fig. 4). Estos detalles sobre los distintos sedimentos deben alertar sobre su cronología y sobre la composición de sus restos cerámicos, pues es posible que gran parte de estos últimos supongan elementos residuales en contextos secundarios.

Ya que E-XIV marca un término post quem para todos los sedimentos que se le superponen, y este estrato es de cronología romana, debemos concluir que una gran parte de la documentación estudiada en el presente artículo corresponde a material arqueológico desplazado de sus ambientes estratigráficos primarios. En relación con la cerámica de barniz negro, esta premisa afecta a toda la ática y a un alto porcentaje de la posterior. El cuadro 1 expresa de manera sintética la correspondencia entre estratos naturales y niveles artificiales de la intervención.

El contexto más profundo con cerámica de barniz negro corresponde, como hemos adelantado, a E-XIV. Incluye los niveles artificiales $\mathrm{N}-36$ y N-35. Aunque su cronología deposicional es romana, contiene cerámica ática en su base (N-36). Es un estrato de formación rápida y color rojo-castaño. Se desconoce la procedencia de su matriz arcillosa, aunque la comarca del Aljarafe, donde se ubica el asentamiento, cuenta con abundante material terciario rubefactado de este tipo en su zona sur, una vieja terraza fluvial del Guadalquivir. Se trata de un barro que se endurece notablemente al secarse, por lo que pudo usarse como tapial para los muros de 


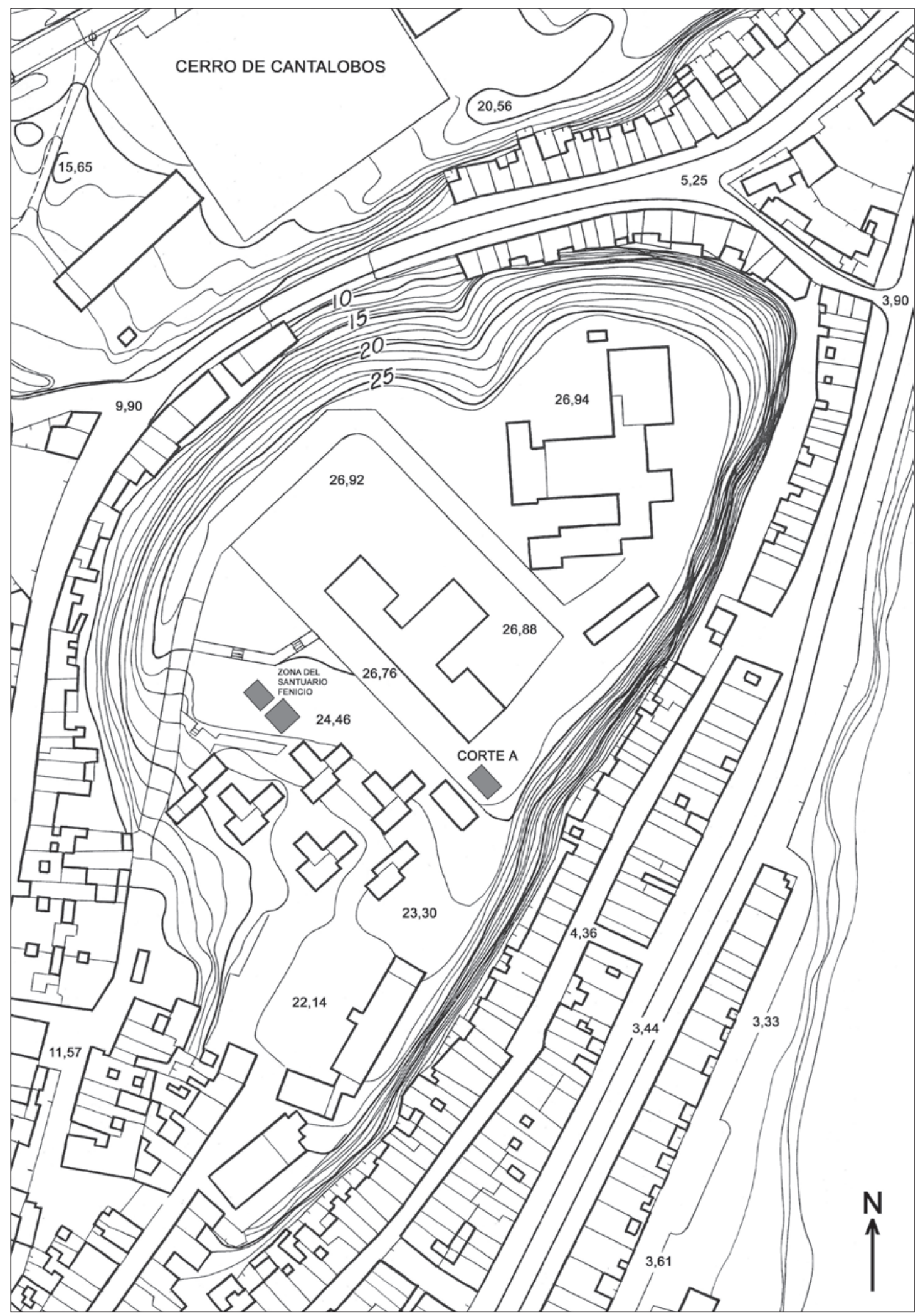

Figura 2. Plano del Cerro de San Juan con ubicación del Corte-A y otras intervenciones.

ISSN: 1133-4525 ISSN-e: 2255-3924

SPAL 24 (2015): 213-235 


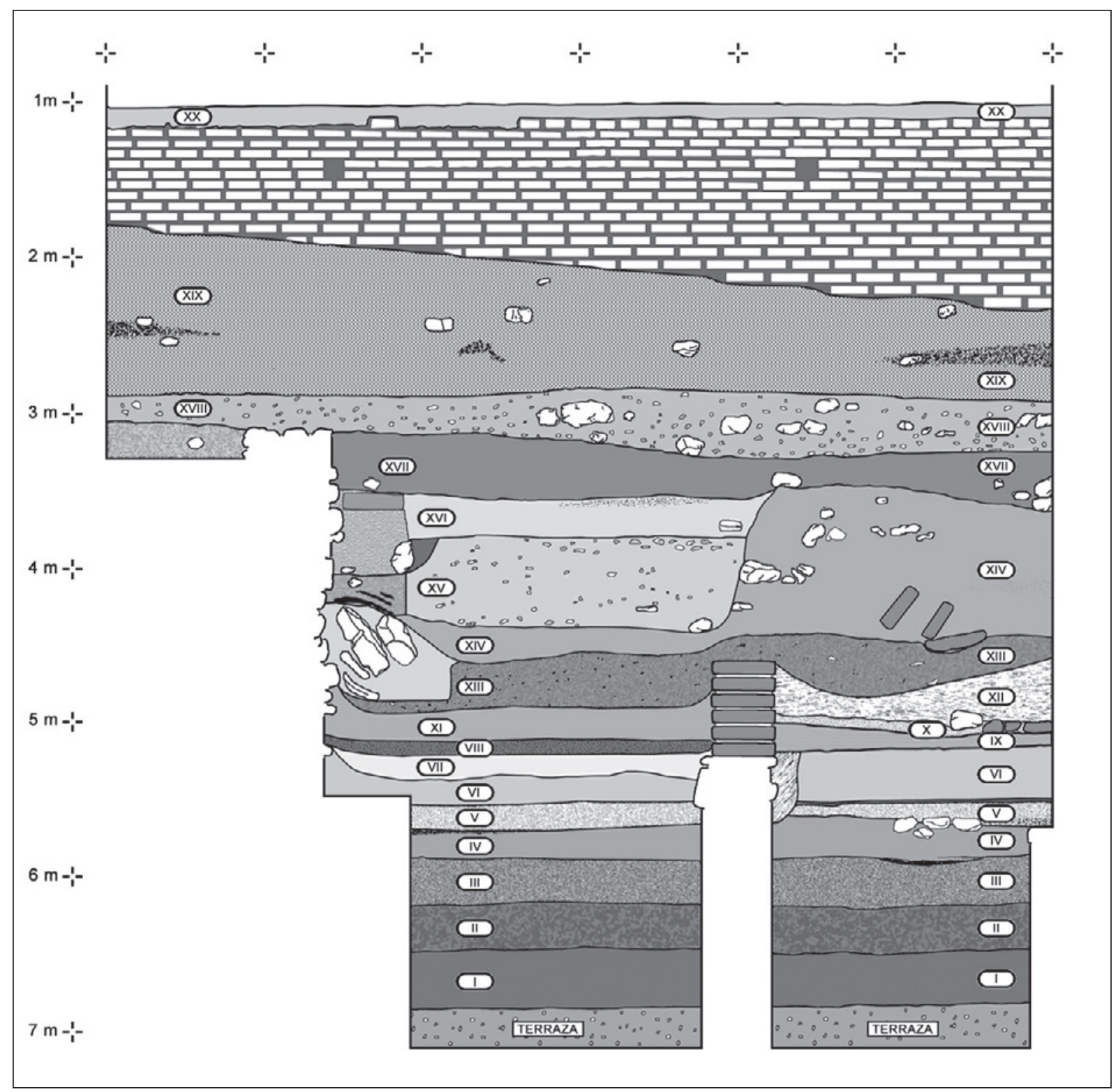

Figura 3. Estratigrafía del Corte-A.

las casas aledañas. De hecho, mezclados con él aparecieron adobes fragmentados y restos de fauna, así como material cerámico que incluye elementos constructivos (ladrillos, tegulae e imbrices). Estos rasgos sugieren que sea el resultado del derrumbe, intencionado o no, de la parte aérea del muro que se apoyaba en el cimiento-zócalo inferior de los tres superpuestos documentados en el flanco norte del sondeo.

Tras la apertura en este estrato rojo de una gran zanja longitudinal, de aproximadamente $1 \mathrm{~m}$ de profundidad, se decanta dentro de la misma un nuevo estrato (E-XV), que incluye los niveles artificiales N-34 y N-33. Se trata de un contexto estratigráfico horizontal de formación lenta. En su base es de color castaño, mientras que se vuelve algo grisáceo en su zona más alta. La matriz de E-XV está compuesta básicamente por arcilla. Contiene abundante material arqueológico, como corresponde a un uso posible como calle a la que se arroja basura. Los múltiples fragmentos de cerámica y de huesos presentes en este estrato le otorgan dureza y compacidad. Es posible vincular con E-XV uno de los tres cimientos apilados ya referidos, aunque 


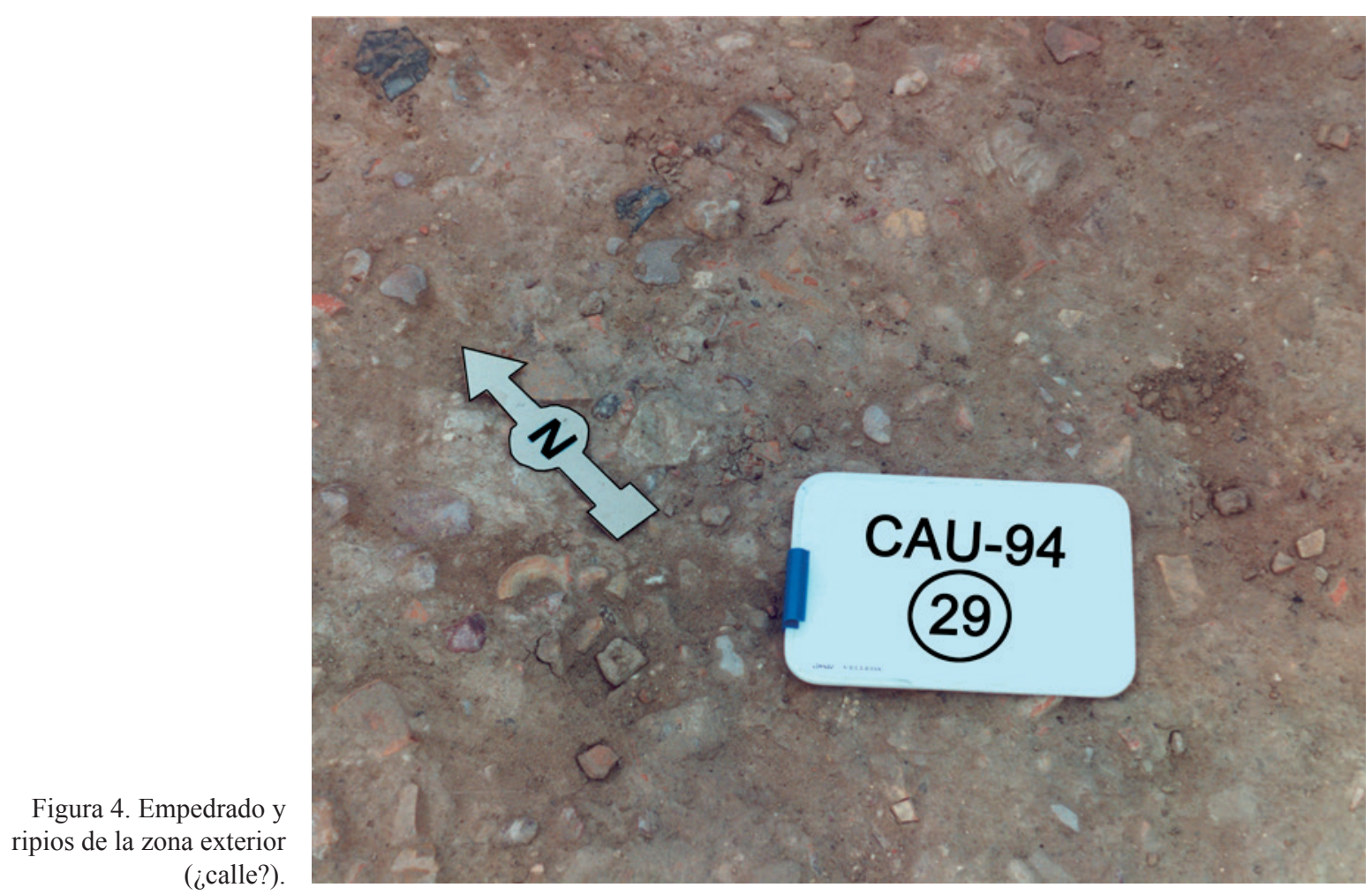

las relaciones estratigráficas estaban poco claras debido a la construcción de un banco adosado a la fachada de esta vivienda, una especie de muelle exterior de tapial que fue retocado con frecuencia. De ser correcta esta relación, E-XV se habría formado mientras se estuvo habitando la casa del cimiento intermedio de los tres superpuestos localizados (fig. 5).

Sobre E-XV, pero dentro todavía del rebaje abierto en E-XIV, se acumula E-XVI. Se trata ahora de un nuevo estrato formado en esta zona de calle, también mediante la decantación lenta de tierras de distinto tipo, mucho material arqueológico y restos de fauna. E-XVI incluye los niveles artificiales N-32, N-31 y N-29. En este caso estamos ante un depósito formado por numerosas manchas de distinta coloración (rojiza, castaña y grisácea), como corresponde a un ámbito, igualmente al aire libre, al que van a parar residuos de muy diversa clase y procedencia. Aquí está más clara la relación estratigráfica con una vivienda aledaña, a la que corresponde el cimiento-zócalo superior de la secuencia de tres localizada al norte del estrato. Se trata de un edificio de muros rectos del que se conoce parte de la fachada y un muro interno en ángulo de $90^{\circ}$ con ésta. Esta pared divide el espacio doméstico al menos en dos estancias. En consecuencia, todo parece indicar que
Cuadro 1. Cerro de San Juan (Caura). Correspondencia entre Niveles artificiales (N) y Estratos (E) en el CorteA. La fecha se refiere a la formación del estrato. Sólo se recogen los contextos con cerámica de barniz negro.

\begin{tabular}{|c|c|c|}
\hline Niveles & Estratos & Datación \\
\hline $\begin{array}{c}\text { N-2 } \\
\text { N-5 } \\
\text { N-7 } \\
\text { N-9 } \\
\text { N-11 } \\
\text { N-13 }\end{array}$ & E-XX & siglo XX \\
\hline $\begin{array}{l}\text { N-15 } \\
\text { N-17 } \\
\text { N-19 }\end{array}$ & E-XIX & siglo XX \\
\hline $\mathrm{N}-21$ & E-XVIII & siglo $\mathrm{XX}$ \\
\hline $\begin{array}{l}\mathrm{N}-23 \\
\mathrm{~N}-26 \\
\mathrm{~N}-28\end{array}$ & E-XVII & siglo $\mathrm{XX}$ \\
\hline $\begin{array}{l}\mathrm{N}-29 \\
\mathrm{~N}-31 \\
\mathrm{~N}-32\end{array}$ & E-XVI & siglo I \\
\hline $\begin{array}{l}\mathrm{N}-33 \\
\mathrm{~N}-34\end{array}$ & E-XV & siglo I \\
\hline $\begin{array}{l}\mathrm{N}-35 \\
\mathrm{~N}-36\end{array}$ & E-XIV & siglo I \\
\hline
\end{tabular}


E-XVI se formó mientras esta casa se mantuvo en pie, y que parte de sus materiales arqueológicos corresponden a las actividades llevadas a cabo por sus ocupantes.

Asociadas a estos dos últimos estratos (E-XV y E$\mathrm{XVI}$ ), y mezcladas con numerosos fragmentos de cerámica muy rodada, aparecen las cápsulas lenticulares de gravilla antes aludidas, que refuerzan la idea de que se trata de un espacio exterior por ser producto de una técnica ampliamente documentada como solución para drenar aguas de lluvia.

En la secuencia estratigráfica se superpone a los contextos anteriores E-XVII. Se trata ahora de un paquete sedimentario que incluye los niveles artificiales $\mathrm{N}-28, \mathrm{~N}-26$ y N-23. Aunque este estrato se adosa por el norte a un cimiento-zócalo de una casa romana -con lo que pudo decantarse en parte en época antigua-, su cerámica vidriada y sus elementos constructivos contemporáneos aconsejan datar su formación en el siglo XX, e interpretarlo como el primer relleno de nivelación de época actual aunque contenga cerámica antigua. Se trata de una capa de tierras de distinta coloración y compacidad, normalmente ocres, castañas y rojizas, fácilmente relacionables con la construcción ya citada del IES Caura. Es posible que, por su abundante material arqueológico, provengan de las zanjas de cimentación de dicho edificio o del aterrazamiento del promontorio para su adecuación como espacio exterior de las aulas.

Esta misma explicación debe atribuirse al estrato situado inmediatamente por encima: E-XVIII. Se trata del primero - en orden cronológico- que selló todos los restos de la Antigüedad, ya que cubre también el muro romano más reciente. E-XVIII equivale a un solo nivel artificial: N-21. Se trata de un sedimento intencional $\mathrm{y}$ rápido, con tierras relativamente homogéneas de color gris. Contiene materiales arqueológicos antiguos y modernos, incluidos trozos de ladrillos actuales. Por su poca fertilidad arqueológica y por la escasez de materia orgánica si se le compara con otros estratos, parece estar formado en parte por tierras, arenas y escombros sobrantes de las obras del Instituto aledaño. Por tanto, debe fecharse también en los años 60 del siglo XX.

Similar función puede atribuirse al estrato que se le superpone: E-XIX. Este paquete incluye los niveles artificiales $\mathrm{N}-19, \mathrm{~N}-17$ y N-15, con colores que van desde el rojizo al castaño y con materiales antiguos y contemporáneos mezclados. Entre estos últimos, los más recientes corresponden a elementos de construcción del siglo pasado. Se incluyen aquí también algunos pequeños paquetes estratigráficos con abundantes fragmentos de carbón vegetal, sin duda resultado de las actividades llevadas a cabo con motivo de las obras del
IES Caura. Por encima de este nivel, aunque sólo en el sector cercano al perfil oriental del sondeo de 1994-96, se localizó un muro de ladrillo perteneciente al flanco oeste de una rampa para vehículos, primer acceso a la plataforma superior del cabezo desde la zona media de éste, la que ocupan las aulas infantiles del Colegio San Juan. Por ello, dicho muro presenta su base inclinada hacia el sur, como puede observarse en el dibujo de la estratigrafía.

Finalmente, toda la secuencia está sellada por el estrato de superficie (E-XX), un conjunto heterogéneo que incluye los siguientes niveles: N-13, N-11, N-9, $\mathrm{N}-7, \mathrm{~N}-5$ y N-2. Aunque todos contenían material arqueológico antiguo y tierras de diversa coloración y textura, se trata también de un estrato formado en época contemporánea, todo él rematado a techo por una fina capa de albero amarillento casi estéril que formaba el nivel de uso en el momento de la excavación.

Aparte de estos estratos horizontales, en momentos medievales se excava un pozo negro (E-30) cuyo relleno posterior vaciamos en dos niveles artificiales: N-30.1 (superior) y N-30.2 (inferior). De este contexto proceden también algunas cerámicas de barniz negro.

Los materiales arqueológicos aquí analizados se encuentran depositados en el Museo Arqueológico de Sevilla. Para su estudio se identificaron individualmente con siglas alusivas al topónimo antiguo del lugar (CAU) y al año de intervención (94), seguidas de la indicación del nivel artificial de procedencia $(17,21,23$, etc.) y del número concreto de cada pieza $(1,2,3 \ldots)$.

\section{LAS CERÁMICAS DE BARNIZ NEGRO}

En este trabajo sólo estudiamos los conjuntos de fragmentos pertenecientes a los tipos de cerámicas de barniz negro recuperados en la excavación llevada a cabo en el Cerro de San Juan en 1994. Las actividades de 1996 en este mismo sondeo no proporcionaron barros de este tipo.

Los conjuntos citados se corresponden con variedades de cerámica que estuvieron en uso y en el mercado de objetos de prestigio entre los siglos V y I a.C. Se trata en concreto de vajillas áticas e itálicas, así como de producciones que, a imitación de aquellas y al amparo de su éxito, surgen y se distribuyen por el occidente atlántico de la península ibérica y la vecina área norteafricana. En este último lote se incluye también la cerámica tipo Kuass, cuyos testimonios procedentes de Caura se han estudiado en otro lugar (Escacena y Moreno 2014), pero también las diversas producciones de 


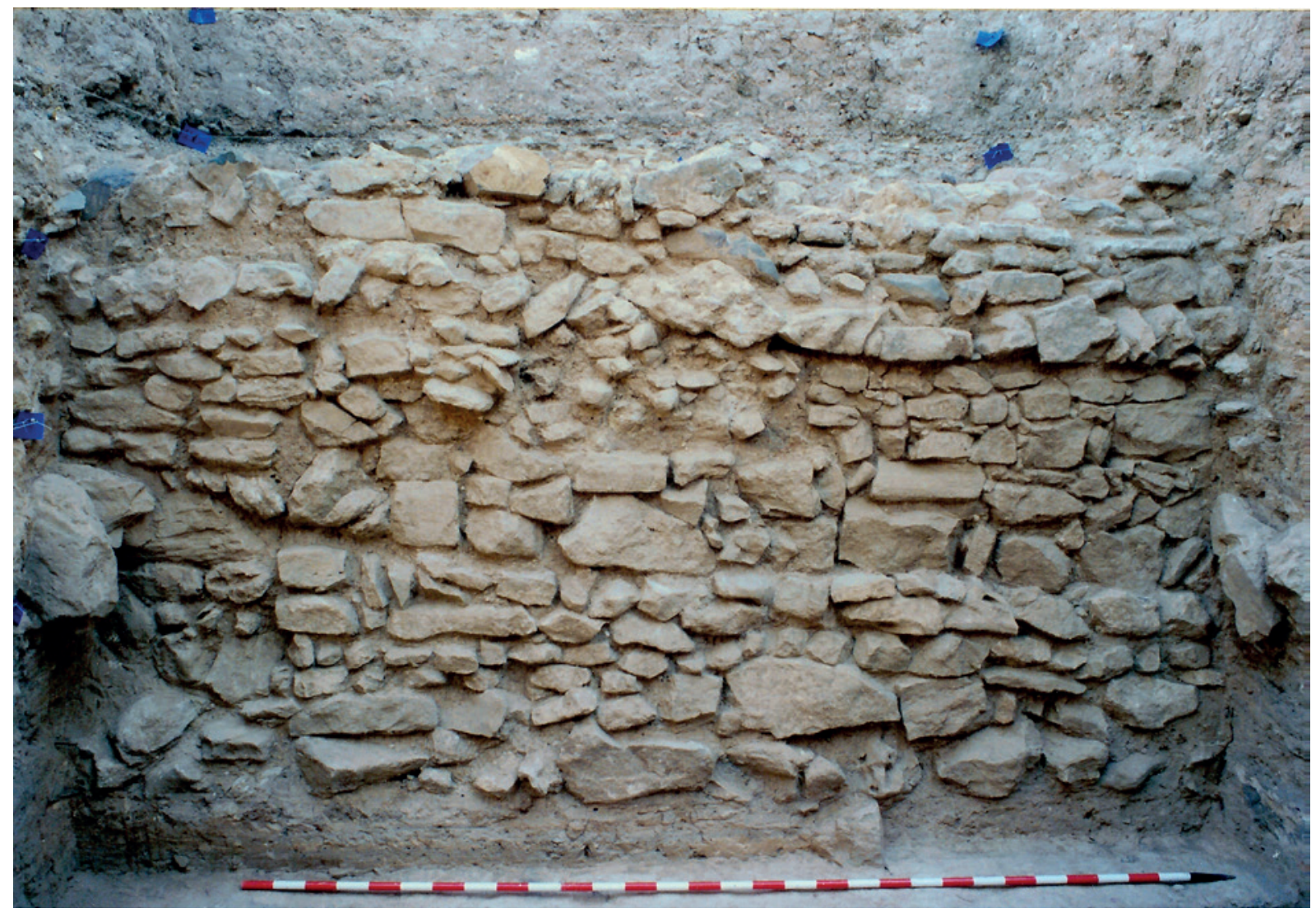

Figura 5. Corte-A. Tres cimientos superpuestos.

pasta gris y barniz negro cuyas formas y decoración imitan claramente las producciones centromediterráneas o se inspiran en ellas (Ventura 1985).

El total de la muestra estudiada se compone de 245 fragmentos, correspondiendo 52 a recipientes áticos, 175 a barros itálicos y 18 a otras producciones occidentales de barniz negro. Denominaremos así a estas últimas mientras no se identifiquen con seguridad sus alfares en el Suroeste ibérico y en el Marruecos atlántico. Todos ellos serán analizados, de mayor a menor antigüedad, en los apartados siguientes (cuadro 2):

El grado de rotura de la muestra es muy alto. Son escasos los fragmentos que sobrepasan los $5 \mathrm{~cm}$, perteneciendo muy pocos a la misma pieza. Este hecho tiene su explicación en el ya aludido uso como calle o espacio de tránsito de algunos de los ámbitos exhumados, donde la cerámica "vieja" o quebrada era amortizada como material para relleno y bacheo. Los resultados de excavaciones más recientes en el cabezo, llevados a cabo en una zona muy próxima a la que nos ocupa, permiten ampliar la explicación de la alta fragmentación de los materiales que analizamos y de su dispersión en la secuencia estratigráfica, ya que pudo comprobarse que gran parte de la cerámica antigua se encontraba en un contexto secundario, reutilizada como material de construcción (Henares 2011). En este otro caso se trata concretamente de su uso como áridos en tapiales y morteros medievales, a cuyas mezclas se añadían después de un concienzudo proceso de machacado para reducir su tamaño. En el Corte-A, el proceso de dispersión $\mathrm{y}$ erosión de la muestra se incrementó en el siglo XX, cuando importantes movimientos de tierra relacionados con la construcción de los edificios próximos volvieron a romper los estratos y a reubicar sus contenidos arqueológicos.

Por lo que concierne a su clasificación formal, y dado que no contamos con ningún recipiente completo ni con un porcentaje de los mismos suficiente, renunciaremos a la terminología tipológica de Morel (1981) para seguir la más general de Lamboglia (1952), con la excepción de la vajilla ática. Para esta última usaremos la nomenclatura clásica, con referencias a las equivalencias con la de Lamboglia (1952), así como otros términos aplicables a ciertas formas utilizados 
Cuadro 2. Asignación de los materiales estudiados por cantidades absolutas.

\begin{tabular}{|l|c|l|c|}
\hline \multicolumn{1}{|c|}{ Clase cerámica } & Fragmentos & Variedad & Fragmentos \\
\hline Griega - Ática & 52 & & \\
\hline Itálica & 22 & & \\
\hline De Cales & 22 & & \\
\hline Campaniense A & 2 & & 136 \\
\hline Campaniense B & 148 & Campaniense B de Cales & 12 \\
\hline Círculo de la Campaniense B & 1 & Otras & \\
\hline Campaniense C & 18 & & \\
\hline Producciones occidentales & 245 & & \\
\hline Total & 18 & & \\
\hline
\end{tabular}

en la literatura arqueológica, como, por ejemplo, para la cerámica del Ágora de Atenas por Sparkes y Talcott (1970) y/o la sistemática de Morel (1981).

\subsection{La cerámica ática}

La aparición de fragmentos de diversas piezas cerámicas de procedencia ática en el yacimiento muestra que Caura se integraba plenamente dentro de la extensa zona de difusión de la alfarería griega por el Mediterráneo occidental. En los siglos V y IV a.C. esta producción llegaba a las costas hispanas y, a partir de Gades y Ampurias, se redistribuía a otros enclaves del litoral y a ciudades del interior (Cabrera 1994, 1997). La primera muestra de cerámica ática hallada en Coria del Río fue publicada por Fernández Gómez y De la Hoz (1993: 115-117, lám. V). Corresponde a un fragmento de la base de un kylix con decoración de figuras rojas -en adelante FR-, datado a mediados del siglo IV a.C. y hallado en superficie en una ladera del Cerro de San Juan. En la cara interna se representaba un busto de Afrodita de perfil y la figura de un joven alado de cuerpo entero, que los autores interpretaron como el ánodos de la divinidad.

El siguiente hallazgo corresponde al conjunto analizado en el presente artículo. Se trata de 52 fragmentos procedentes de la intervención de 1994 ya citada. Se hallaron en diversos estratos, desde la superficie hasta E-XIV. Muchos de ellos, 28 fragmentos, proceden de E-XV. En el resto de los estratos no parecen existir especiales concentraciones. En cualquier caso, hay que recordar de nuevo que todos los materiales aparecieron en posición secundaria, por lo que deben considerarse elementos residuales según la terminología de E.C. Harris (1991: 166).

La cerámica ática presenta una alta fragmentación, además de un grado de erosión también notable. Por ello, 18 fragmentos han tenido que clasificarse como "indeterminados" dada la imposibilidad de identificarlos adecuadamente. Los demás son bases, pies, bordes y asas, más algunos galbos, carenas o cuellos. En conjunto, su tipología permite sostener un uso relativamente alto en la Caura turdetana de la vajilla ática de importación. En estos servicios primaban las formas abiertas, usadas como copas/vasos para beber (kylix, bolsal, skyphos, phiale) o como platos (pinakiskos), en este segundo caso para el consumo de sólidos o semisólidos. Todo ello aparece acompañado de recipientes cerrados de tamaño pequeño o mediano (olpes), destinados al servicio de líquidos. Junto a estas formas, se documentan también elementos de tocador o pequeños contenedores suntuarios (ungüentario, aríbalos). Otros elementos -dudosos dado el tamaño de los fragmentos y su estado de conservación- corresponden posiblemente a lekithos, a kernos y a un ánfora (o peana de un lebes gamiko), testimonios que apuntan a un panorama cerámico más variado. Para la funcionalidad de los objetos y la composición de esa vajilla seguimos el estudio de Bats (1988).

Por lo que respecta a la decoración, podemos dividir la muestra en las dos variedades clásicas: FR 


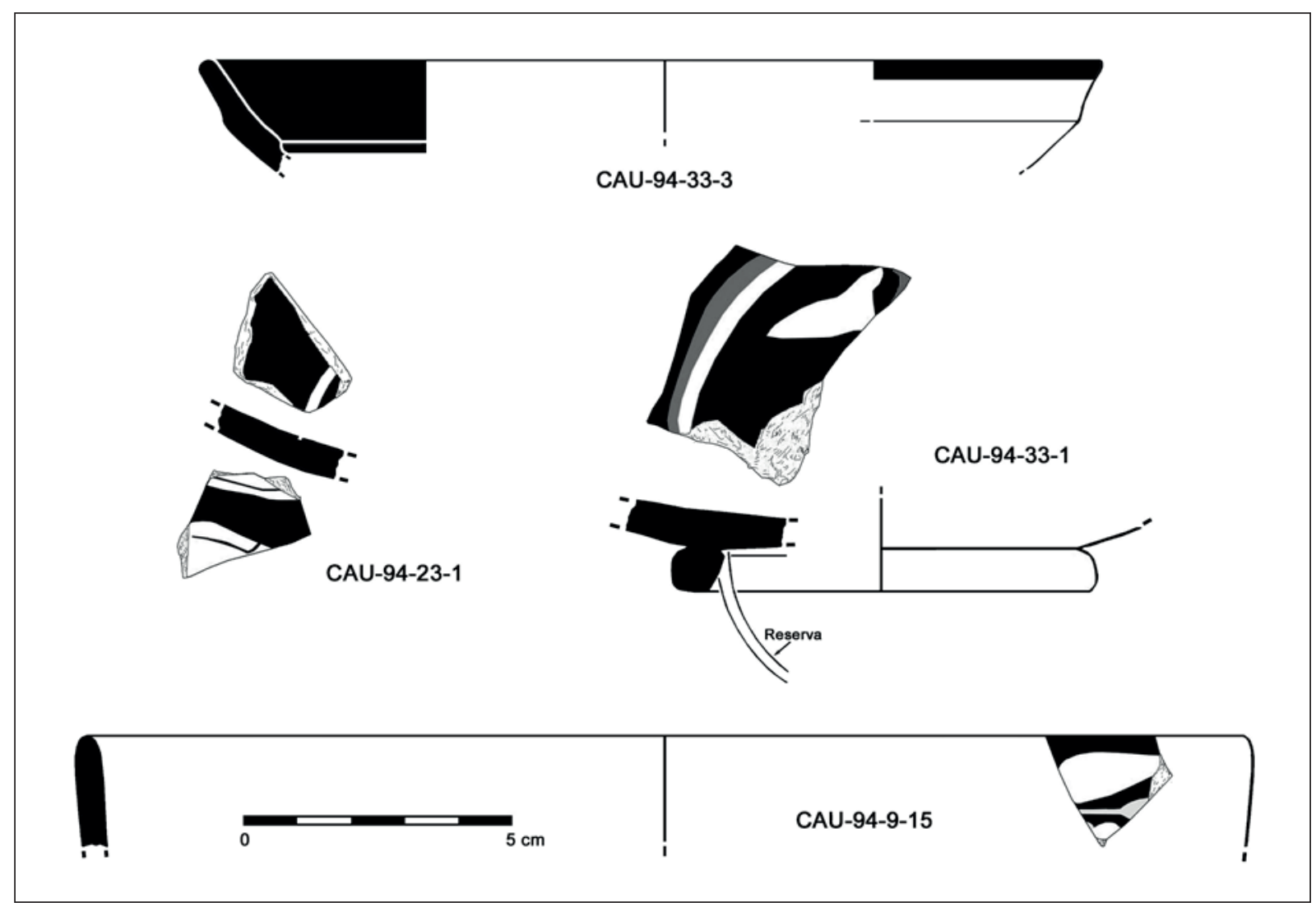

Figura 6. Cerámica Ática de Figuras Rojas.

(Figuras Rojas) y BN (Barniz Negro). De la primera contamos con cinco fragmentos seguros, ya que, dado su pequeño tamaño y que las formas suelen ser comunes a ambas variedades decorativas, no podemos certificar que algunos trozos no pertenezcan a vasos de FR. Estos cinco elementos bien identificados corresponden a cuatro piezas (fig. 6):

- CAU-94-9-15: Fragmento de borde de skyphos/L.43. Conserva restos de decoración al exterior, donde se alternan el fondo barnizado de negro y las zonas de reserva típicas de decoración de FR. Sobre el fondo negro se observa pintura blanca transparente, vestigio de lo que podría ser una cenefa de motivos vegetales estilizados, en concreto un tallo horizontal, una pequeña porción de una hoja ¿de mirto? y parte de una baya.

- CAU-94-33-1: Dos trozos de la base de un kylix de pie bajo (stemless cup/L.42). En la parte superior, restos de una circunferencia en reserva parecen definir un "medallón" central, donde, sobre fondo negro, se aprecia un vestigio de la decoración "en reserva", tan pequeño que quizás sea aventurado pensar que podría tratarse del pie de un personaje. El pie de la copa está barnizado, excepto en una circunferencia en reserva en el ángulo interior de la unión del propio pie con el cuerpo de la copa.

- CAU-94-23-1: Fragmento del cuerpo de un kylix de pie bajo (stemless cup/L.42). Como en el caso anterior, se observa en la parte interna que una circunferencia en reserva -en este caso mucho más fina- delimitaría la decoración pictórica central. En el exterior aparece una decoración más extensa en la que se alternan áreas barnizadas y en reserva. Sobre estas últimas zonas se observan finísimas líneas negras.

- CAU-94-33-3: Borde de kylix. El barniz negro cubría el interior del borde y unos milímetros del exterior, dejando el resto de la superficie en reserva de barniz alrededor del punto de inserción del asa, cuya impronta se conserva.

El skyphos, cuyo borde sugiere asignarlo a la clase de perfil continuo del siglo V a.C., podría ser de uno de los tipos de vasos de FR sobrepintados que llegaron a 


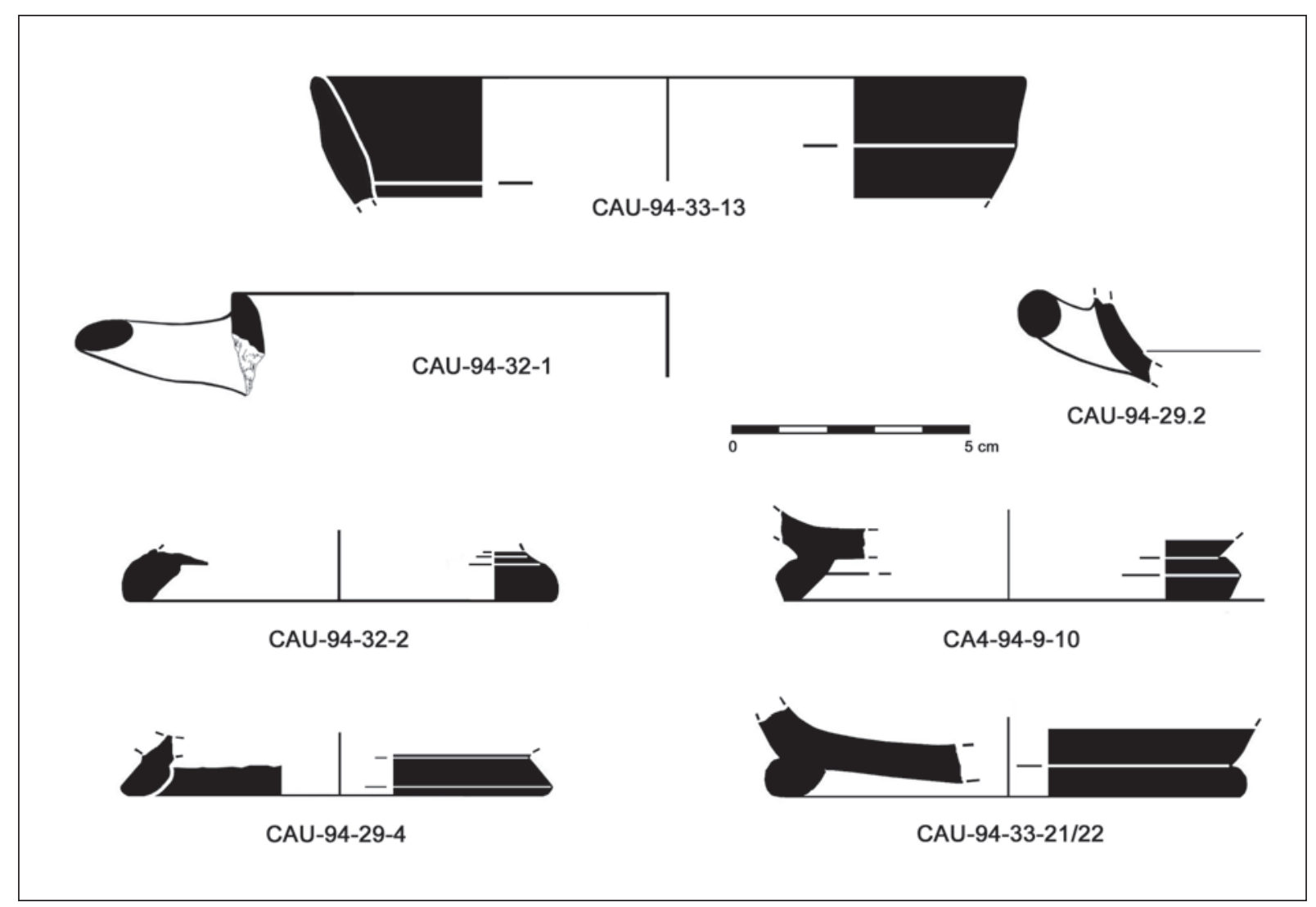

Figura 7. Cerámica Ática de Figuras Negras (ss. V-IV a.C).

la península ibérica en las últimas décadas de ese siglo. Esta variedad se ha documentado también en Huelva (Fernández Jurado 1985: 14-16).

Teniendo en cuenta el estudio analítico de Cabrera (1997: 374-397) sobre las importaciones más características de FR procedentes de Andalucía occidental, las copas podrían asignarse al patrón decorativo "del Círculo de Viena 116", con datación entre los años 380 y 350 a.C. Dicha serie logró en estos años sus cotas máximas de producción y distribución (Rouillard 1991: 123; Cabrera 1997).

Por lo que respecta a la variedad de $\mathrm{BN}$, nos encontramos con elementos típicos de las importaciones que, comenzando en el siglo V a.C., seguirán llegando a los territorios atlánticos andaluces hasta mediados del siguiente. Se trata sobre todo de copas de pie bajo (stemless cups) conocidas como "Copas Cástulo"/L.42$\mathrm{A}^{1}$, de la que es una buena representación el fragmento CAU-94-33-13 (fig. 7). De este recipiente se

1. Para una historia de la denominación de este tipo de copas áticas, Sánchez Fernández (1992: 328). han registrado al menos 4 ejemplares además de varias asas. Junto a esta exitosa forma, la muestra cuenta también con un par de fragmentos de otras copas que, si bien compartieron el mercado con ella durante muchos años, dejaron de importarse hacia principios del siglo IV a.C. Nos referimos a la de la "Clase Delicada"/ L.42-AII. Se trata de un fragmento de arranque de asa, que conserva parte de la cara interna de la vasija, representado por el testimonio CAU-94-29-2 (fig. 7). Igualmente, se constata la copa denominada habitualmente "kylix-skyphos", en este caso el fragmento de pie CAU94-32-2 (fig. 7). Los restantes elementos con datación segura corresponden a partes de otras piezas muy abundantes entre las importaciones del segundo cuarto del siglo IV a.C. De ellas, CAU-94-9-10, CAU-94-294, CAU-94-32-1 y CAU-94-33-21/22 pertenecen al bolsal/L.42Ba, con fragmentos de pie/base de tres piezas distintas, así como con parte del borde con asa de otra y con los restos de, al menos, dos asas más (fig. 7). Dos pies de sendos vasos, siglados como CAU-94-32-3 y CAU-94-33-8, obedecen a la forma skyphos (fig. 8). Todas las piezas aludidas en este párrafo las incluimos 


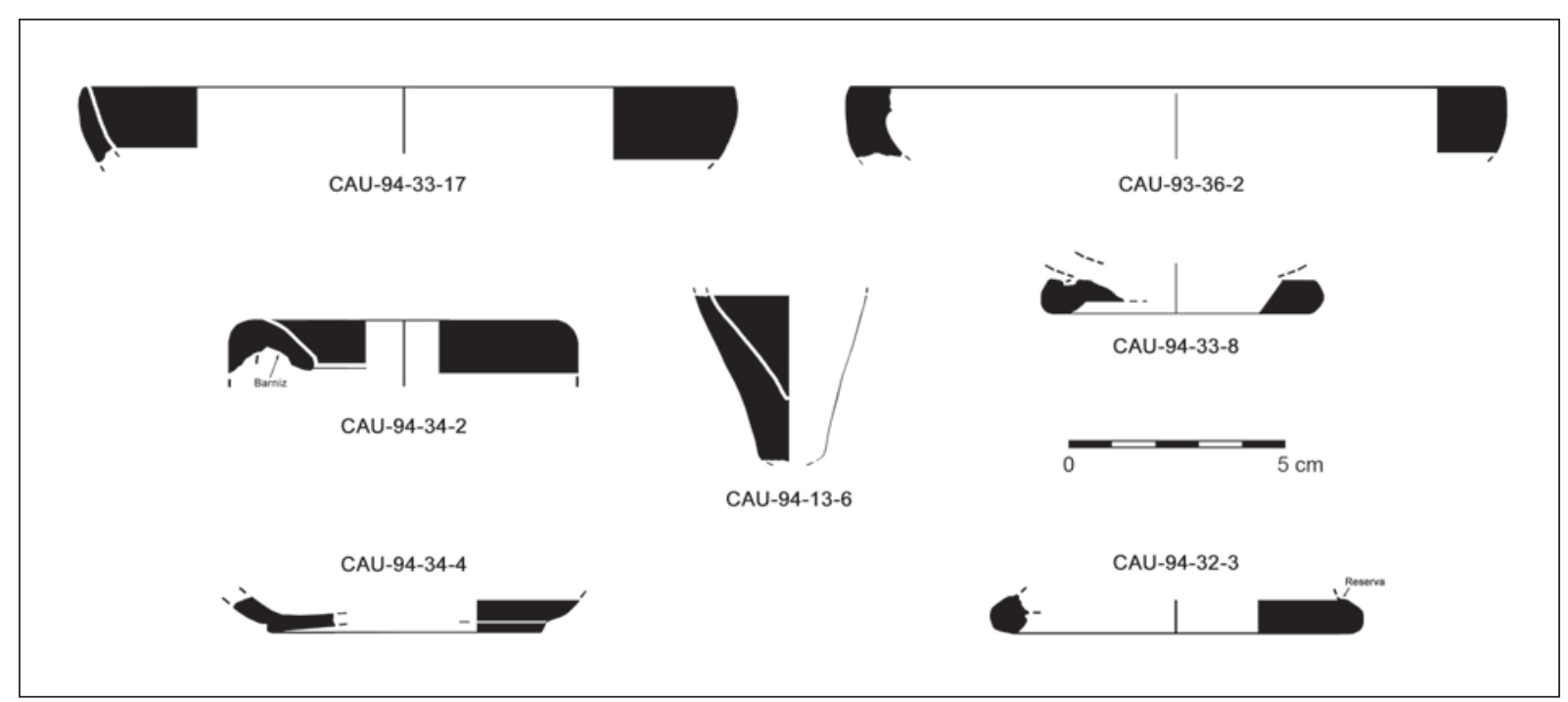

Figura 8. Cerámica Ática de Figuras Negras (s. IV a.C).

entre los materiales de $\mathrm{BN}$, aunque sin descartar que formaran parte de recipientes con FR, ya que en Huelva también se han documentado restos de skyphos decorados siguiendo el patrón del denominado "Grupo del Fat Boy" (Cabrera 1997: 379).

En relación con el resto de fragmentos, contamos con varios pertenecientes a formas abiertas. De este grupo, CAU-94-33-17 supone una pequeña parte del borde de una copa sin pie y con ónfalo central/phiale (fig. 8), mientras que CAU-94-36-2 perteneció a un plato/plate/pinakiskos, probablemente del tipo rolled rim plate de Sparkes y Talcott (fig. 8). Además, en la muestra hay fragmentos que, si bien pueden corresponder a este tipo de piezas, los hemos contabilizado como "indeterminados" por su pequeño tamaño y mal estado de conservación; igualmente, un pie que por su forma, desarrollo y característica "uña" en la superficie de apoyo podría pertenecer a un plato o patera, podría ser en realidad una forma distinta por su baquetón decorativo externo y su peana de mayor longitud (¿kernos? ¿krateriscos?). Finalmente, a formas cerradas sólo pueden asignarse con certeza los tres fragmentos que describimos a continuación (fig. 8):

- CAU-94-34-4: Parte de la base de un olpes, con el pie apenas indicado característico de estas piezas áticas producidas entre los siglos $\mathrm{V}$ y IV a.C. $\mathrm{Su}$ barniz, muy deteriorado, puede inducir a duda a la hora de considerarla una producción ática.

- CAU-94-34-2: Fragmento del borde de un aríbalos. Aunque roto, conserva extraordinariamente bien el barniz.
- CAU-94-13-6: Parte del tercio inferior de un ungüentario, al que le falta el pie. El exterior del aparece en reserva, mientras que el interior conserva bien el barniz. Por su desarrollo, podría ser un ungüentario fusiforme de cuello largo con barniz al interior, una forma de la serie 7111 de Morel, paralela a las denominadas $\mathrm{C} 3$ o $\mathrm{C} 4$, descritas por $\mathrm{Mu}$ ñoz (1988).

Los fragmentos de difícil adscripción son un trocito del cuello de una forma cerrada de tamaño pequeño (¿ungüentario, perfume pot, bombylios, lekithos?) y paredes muy finas, con barniz negro en ambas caras; y un fragmento del galbo de una pieza de tamaño grande (por su desarrollo, podría pertenecer a un ánfora o a la peana de un lebes gamiko).

A la vista de la muestra analizada, las cerámicas áticas estuvieron llegando a Caura desde finales del siglo V hasta mediados del IV a.C., aunque sin descartar que pudiera haberse recibido alguna todavía en la segunda mitad del mismo.

Por lo que respecta a su utilización, la vajilla ática de Caura sigue también la que podríamos llamar "norma de occidente", ya que se emplean y amortizan en la zona de hábitat de la ciudad, mientras que en la zona oriental de la península ibérica se destinan básicamente a las necrópolis (Cabrera 1994: 91). Esto supone la posibilidad de que en esta ciudad turdetana los ungüentarios tuvieran funciones diferentes a la funeraria, fuera doméstica y/o religiosa. Tampoco habría que desestimar otro uso poco tratado en 
la bibliografía arqueológica, como sería el médico o farmacológico.

Las piezas de Caura se corresponden con importaciones áticas documentadas en la zona más occidental de la costa del Golfo de Cádiz y en algunas áreas cercanas: Huelva, Castro Marim, Rocha Branca y Mértola (Luís 2003). Dada la condición de ciudad costera y portuaria que entonces tenía Caura, y porque la cerámica ática "no es una mercancía generalizada, ni un producto ampliamente distribuido" (Cabrera 1997: 377), su abundante presencia en este enclave turdetano indica que estamos ante un centro de consumo con cierta prosperidad local derivada del comercio. Las ánforas de la época apoyan esta misma conclusión. De todos estos testimonios puede deducirse que Caura fue una escala fundamental en el tráfico mercantil hacia el interior, principalmente de las manufacturas y productos helénicos llegados a través del gran centro redistribuidor de Gadir.

\subsection{Primeras piezas itálicas de barniz negro (cerámica de Cales) y producciones occidentales}

Entre el siglo III y el II a.C. se produce en la Italia central un tipo de cerámica fina de alta calidad, con decoración en relieve, denominada en la literatura arqueológica Cerámica de Cales (o cerámica calena). Aunque esta variedad llegó a muchos lugares del Mediterráneo occidental, lo hizo siempre en cantidades muy limitadas (Beltrán 1990: 40; Abad 1983: 187-189). En el Corte-A de Caura se hallaron dos fragmentos en el nivel artificial $\mathrm{N}-17$, perteneciente al estrato de época contemporánea E-XIX. Por tanto, estamos también ante elementos residuales.

Por lo que respecta a su morfología, una pieza resulta inclasificable por su pequeño tamaño y su fuerte erosión. Por su parte, el otro fragmento permite un análisis más detallado. Se trata de parte de la decoración figurativa en alto relieve de una patera umbilicata (o phiale mesomphala, según la bibliografía que se consulte). La pieza, siglada como CAU-94-17-10 (fig. 9 y 10), es un pequeño fragmento $(2,5 \times 2,2 \mathrm{~cm})$ de la pared de una phiale ${ }^{2}$. Conserva parte del motivo

2. Como adelantamos en el apartado referido a la cerámica ática, una phiale era un vaso para beber, sin pie y con un ónfalo central. Esta clase de copa se asía con dos dedos, uno en el ónfalo y otro en el borde, conforme a las normas griegas de la etiqueta de mesa. Podía llevar decorado el interior. figurativo, que la decoraba formando una orla alrededor del ónfalo o umbilicus central. Se aprecia claramente una figurilla humana alada, conforme a la iconografía de Eros en edad infantil-juvenil con alas de ave. Igualmente, presenta restos de una guirnalda de motivos vegetales estilizados. El pequeño Eros mira y tiende los brazos hacia la derecha, donde se encuentra con una figura similar en posición simétrica o se abraza a ella. La fractura del fragmento nos priva de detalles que podrían acabar de confirmar el tema decorativo. De hecho, si el personaje de la derecha era totalmente simétrico y se trataba de otro Eros juvenil, el tema iconográfico sería el de Eros/Anteros. Pero, si la figura de la derecha tuviera rasgos femeninos $\mathrm{y}$, probablemente, alas de mariposa en lugar de alas de ave, el tema representado sería el de Eros y Psique.

En La Serreta (Alcoy) se encontró un fragmento de este tipo de páteras (Abad 1983: 180-181, fig.2). En este caso la decoración consiste en una orla que repite un motivo de Eros infantil, "volando" entre roleos vegetales y motivos florales muy estilizados, composición que podría parecerse a la de nuestro ejemplar. Este hallazgo viene a unirse a los escasos ejemplos de cerámica decorada en relieve registrados hasta la fecha en el ámbito territorial que nos ocupa: el fragmento de base con decoración central procedente de Asta Regia, que se conserva en el Museo de Jerez de la Frontera (Cádiz), y los ejemplares procedentes de Corduba e Italica, relacionables tipológicamente con la llamada "Serie F1153" de Morel (Ventura 2000 y 2001).

De todas formas, el testimonio de Caura supone tal vez el hallazgo más occidental de una de estas piezas. Al tratarse de una vajilla lujosa, este hallazgo parece indicar que, al menos en su época de mayor actividad exportadora desde Italia, entre mediados del siglo III y principios del siglo II a.C., a Caura llegaban productos procedentes de los circuitos comerciales del Mediterráneo central, y que esta ciudad era lo suficientemente próspera como para permitirse adquirir las manufacturas de cerámica más caras del momento.

A esta conclusión debemos añadir, no obstante, que del siglo IV avanzado y del III a.C., cuando llegan a la península ibérica las producciones del "Tipo Gnathia" o del "Taller de las Pequeñas Estampillas", no se han detectado importaciones; tampoco ningún testimonio atribuible a los productos hispánicos, como por ejemplo los del "Taller de las Tres Palmetas Radiales" o los del entorno geográfico de Ampurias/Rhode, de similar cronología (Ventura 2001: 323-324; Sanmartí 1981: 165-169). Esta observación puede aplicarse a los 


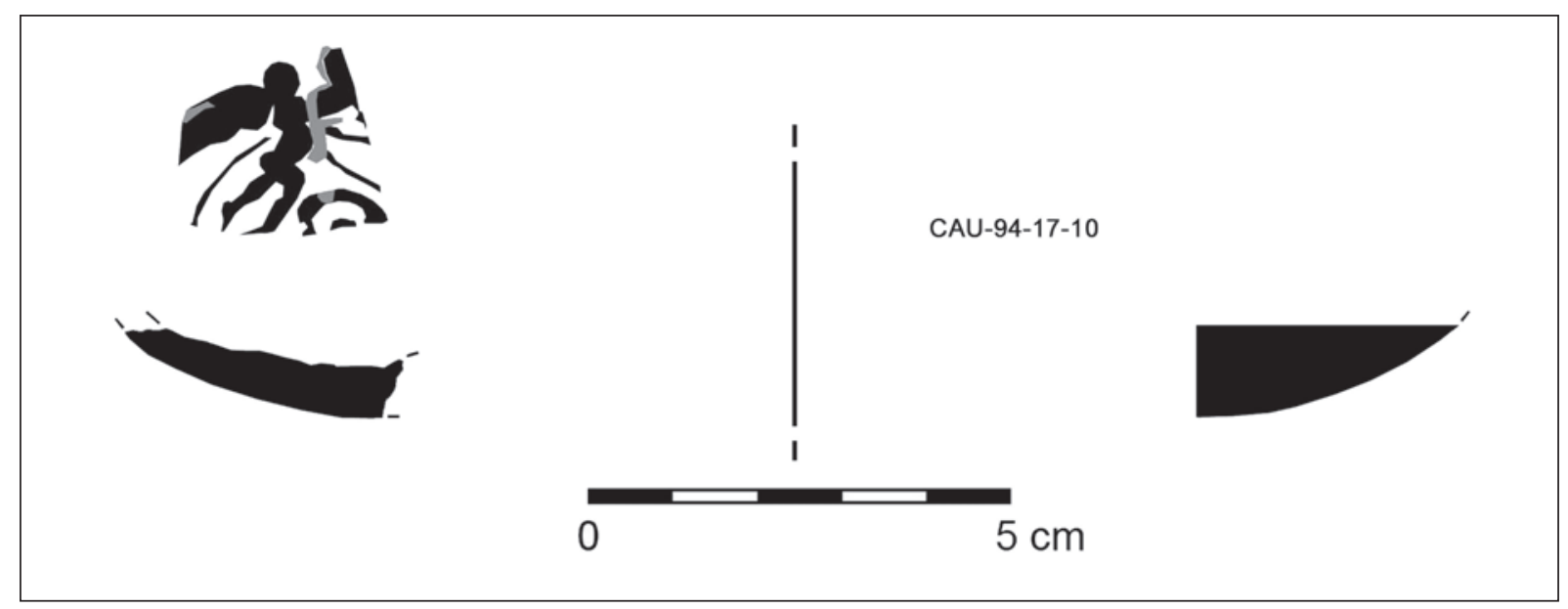

Figura 9. Cerámica de Cales.

productos de otros muchos alfares ya identificados: Taller "de las rosetas nominales", Taller de "las palmetas impresas sobre banda de estrías", Taller "de las pequeñas páteras-L.55", Taller "Nikkia/Ion" y Taller de los kylikes-L.42-c”. A la luz de la documentación actual, parece que la distribución de estos últimos barros no incluyó las costas atlánticas (Pérez 2009).

\subsection{La cerámica itálica de barniz negro conocida como "campaniense"}

Aunque comienzan a exportarse desde la península itálica en el siglo III a.C., estas producciones serán las que acaben por convertirse en las variedades predominantes en el sector del mercado de las vajillas finas de barniz negro en el Mediterráneo occidental, especialmente durante los dos siglos siguientes y al compás de la expansión romana tras la Segunda Guerra Púnica. La Campaniense A, por ejemplo, habría empezado a exportarse en la segunda mitad del siglo III a.C., siendo a partir de su último cuarto cuando se documenta más claramente su llegada a la península ibérica (Sanmartí 1981: 170-171; Beltrán 1990: 40; Ventura 2001: 327).

El conjunto aquí analizado se compone de 173 fragmentos (cuadro 3), que se reparten entre diversas series y que se datan en los siglos II y I a.C. Su procedencia se sitúa en Italia central para la Campaniense A (área del Golfo de Nápoles) y la producción de tipo B de Cales, en la zona norte (Toscana) para la Campaniense B propiamente dicha y en Sicilia para la llamada Campaniense C (Ventura 1985 y 2001: 327-330).

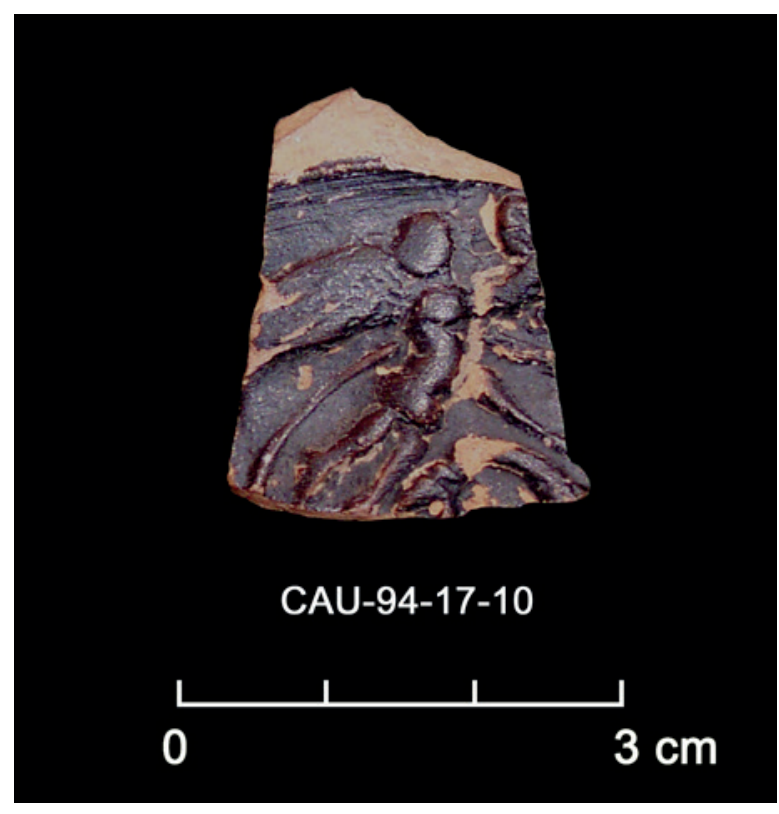

Figura 10. Motivo en relieve de una phiale mesomphala (Cerámica de Cales, CAU94-17-10).

\subsubsection{Campaniense A}

Pertenecen a dicha modalidad 22 fragmentos, todos ellos con los rasgos típicos de esta producción itálica. Su ubicación en los distintos estratos que cuentan con cerámica de barniz negro es bastante regular, pues está presente en E-XVII (N-23), E-XIX (N-15) y E-XX (N-13, N-11, N-9, N-7 y N-5). En cualquier caso, todos estos contextos sedimentarios son de formación contemporánea, por lo que se trata de materiales en 


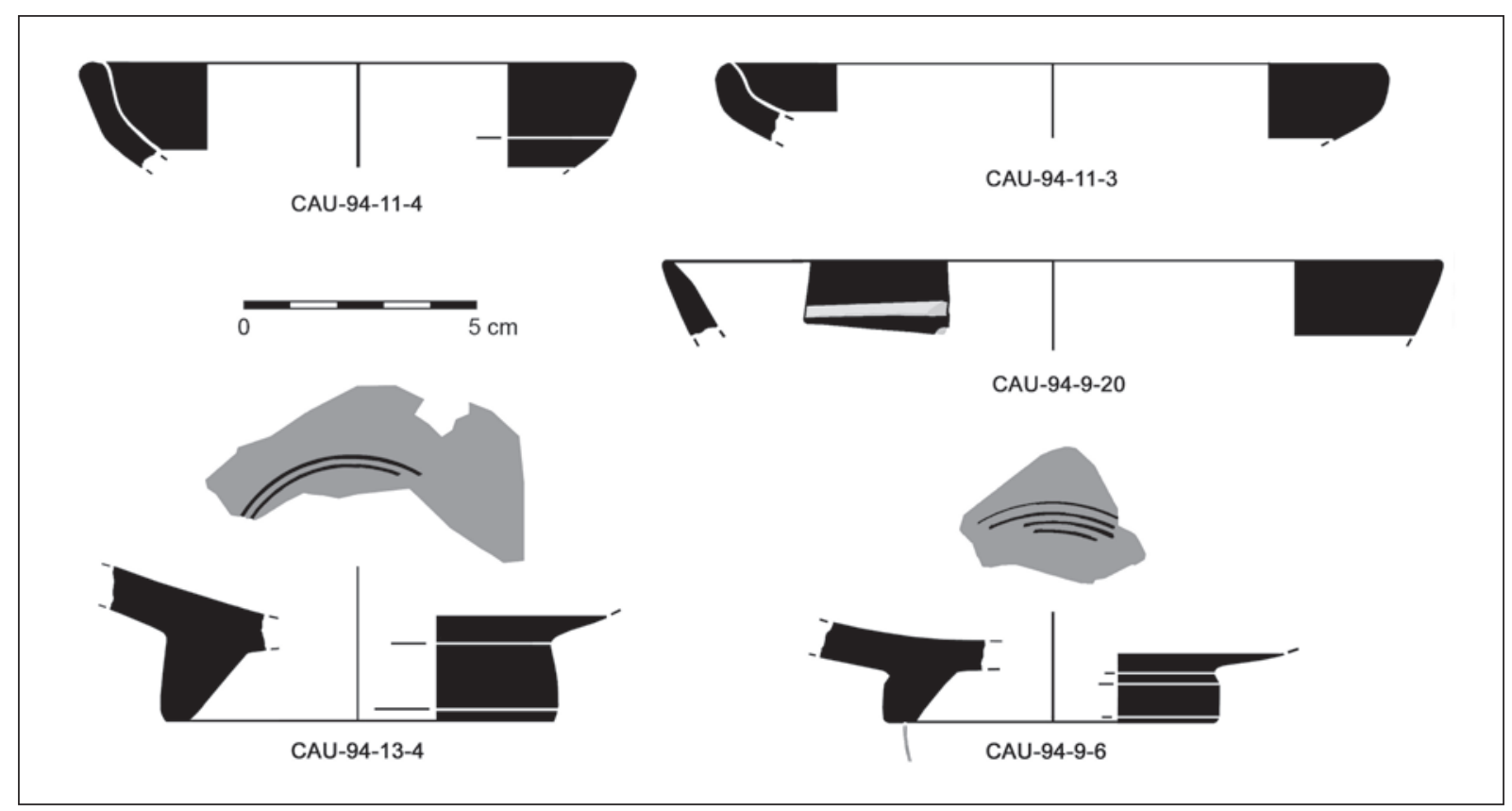

Figura 11. Cerámica Campaniense A.

posición secundaria. No obstante, los elementos arqueológicos antiguos de tales estratos muestran un perfil cronológico relativamente coherente, lo que sugiere que su matriz terrosa se obtuvo básicamente de un sustrato fechable en época romana en términos genéricos. La muestra la forman fragmentos de tamaño pequeño o muy pequeño, de manera que 12 de ellos (54\%) resultan inclasificables si se pretende ir más allá de la asignación específica desde el punto de vista de la tipología formal. Los restantes fragmentos son bordes, bases y pies de formas abiertas.

La tipología de formas reconocibles se concreta en las Lamboglia 5, 6, 27c, 31 y 36, presentes en el repertorio ya documentado en Andalucía occidental (Ventura 1990 y 2001) y sur de Portugal (Luís 2003). Como avance sobre la vajilla que se importaba en Caura en esta época, podemos afirmar que parece estar formada preferentemente por páteras y boles/cuencos. En cuanto a su decoración, sólo estas tres piezas conservan restos de haberla tenido (fig. 11):

- CAU-94-9-20: Fragmento de borde de la forma Lamboglia 31, con una banda pintada en blanco al interior, datable en el siglo II a.C.

- CAU-94-9-6: Base de pátera (forma imprecisa) con círculos acanalados.

- CAU-94-13-4: Fragmento de base de la forma Lamboglia 6 , con círculos acanalados, fechable en el siglo I a.C.
La vajilla de la Campaniense A se usó en Caura durante la época de máxima actividad exportadora de los talleres de origen. Por tanto, a lo largo del siglo II a.C. la vida comercial de su puerto seguía prósperamente conectada con el flujo internacional que llegaba a las costas del suroeste ibérico desde el Mediterráneo central, del que el tráfico de cerámica era sólo una parte. Como señaló Sanmartí (1981: 177), esta vajilla viajaba como complemento de carga en los navíos dedicados mayoritariamente a la exportación de vinos desde Italia.

\subsubsection{El "Círculo de la Campaniense B"}

Se trata de producciones que llegan a la península ibérica prácticamente desde que surgen en el siglo II a.C., acaparando la mayor cuota de mercado a lo largo de esta centuria y de la siguiente (Beltrán 1990; Sanmartí 1981: 174-175). Un reflejo de esta situación sería el mayor número de fragmentos (por oposición a los tipos A y C) hallados en la intervención de 1994 en Caura. Contamos ahora con 150 fragmentos con barnices, pastas, tipología y decoración típicos del "círculo de la Campaniense B", que se reparten entre la Campaniense B, la Campaniense B de Cales -también denominada "de tipo Cales" o, anteriormente, "B-oide"- y otras afines (Ventura 2001: 328-335). 


\subsubsection{Campaniense B}

Sólo dos fragmentos de la muestra analizada corresponden a productos de tipo B "clásico", con origen en talleres etrusco-toscanos. Proceden de E-XX. Morfológicamente, se trata de dos trozos de galbo. Uno corresponde a un ungüentario o a un pequeño recipiente cerrado; otro puede asignarse probablemente a una forma abierta (L.6), aunque su tamaño y mala conservación impiden precisar más.

\subsubsection{Campaniense B de Cales}

Se trata del grueso de la muestra, 136 fragmentos, lo que proporciona una idea bastante clara de lo abundantes $-\mathrm{y}$ populares entre los consumidores- que fueron estas vajillas en la Caura de los siglos II y I a.C.

Morfológicamente, se trata de bordes y bases, en este último caso pies y parte del fondo de formas abiertas. Hay además algunos galbos y carenas. La fragmentación es muy alta, ya que sólo una pieza llega a representar el 35\% del recipiente (fig. 12). Si a esto sumamos la erosión, resultan inclasificables 50 fragmentos. Por lo que respecta a su tipología, el repertorio está formado por L.1, L.2, L.3 (fig. 13), L.4, L.5, L.5/7 (fig. 14), L.6, L.7, L.8, L.8b y L.10, en una muestra de la vajilla típica de estas producciones cerámicas,

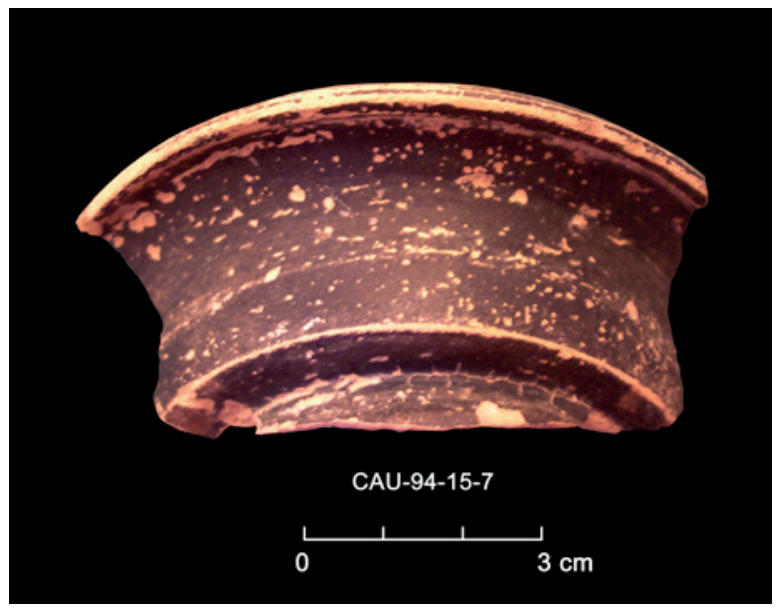

Figura 12. Detalle de copa L2. Cerámica Campaniense B de Cales (CAU94-15-07).

formada por páteras, boles/cuencos y copas, más algunos elementos de servicio.

En cuanto a decoración, en el lote están presentes los característicos círculos acanalados, acompañados en ocasiones por orlas o coronas de estrías. El vestigio de mayor interés se encuentra en un trozo de la base de una pátera siglada como CAU-94-5-19, decorada con un emblema losángico (fig. 15).

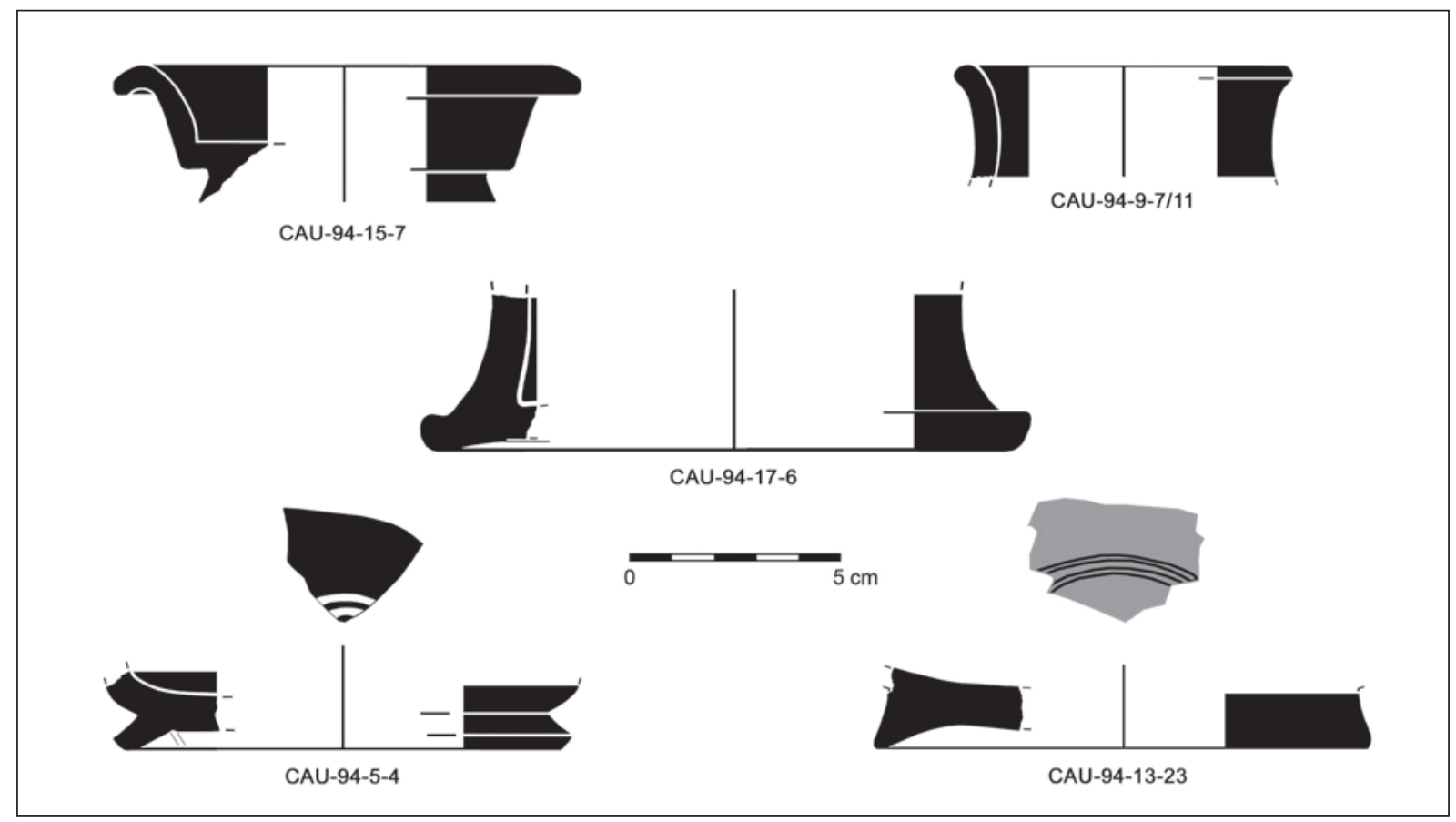

Figura 13. Cerámica Campaniense B (de Cales). Formas L1, L2 y L3. 


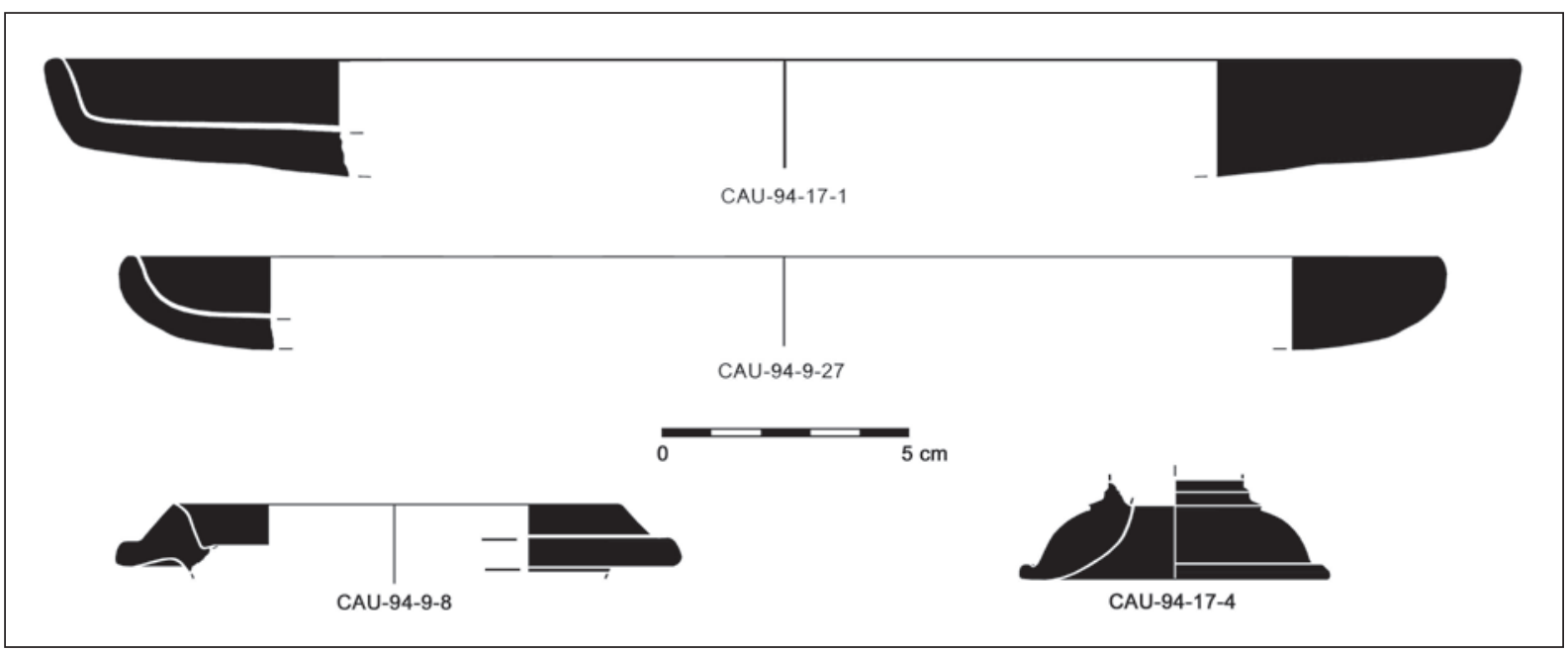

Figura 14. Cerámica Campaniense B (de Cales). Formas L4, L5 y L5/7.

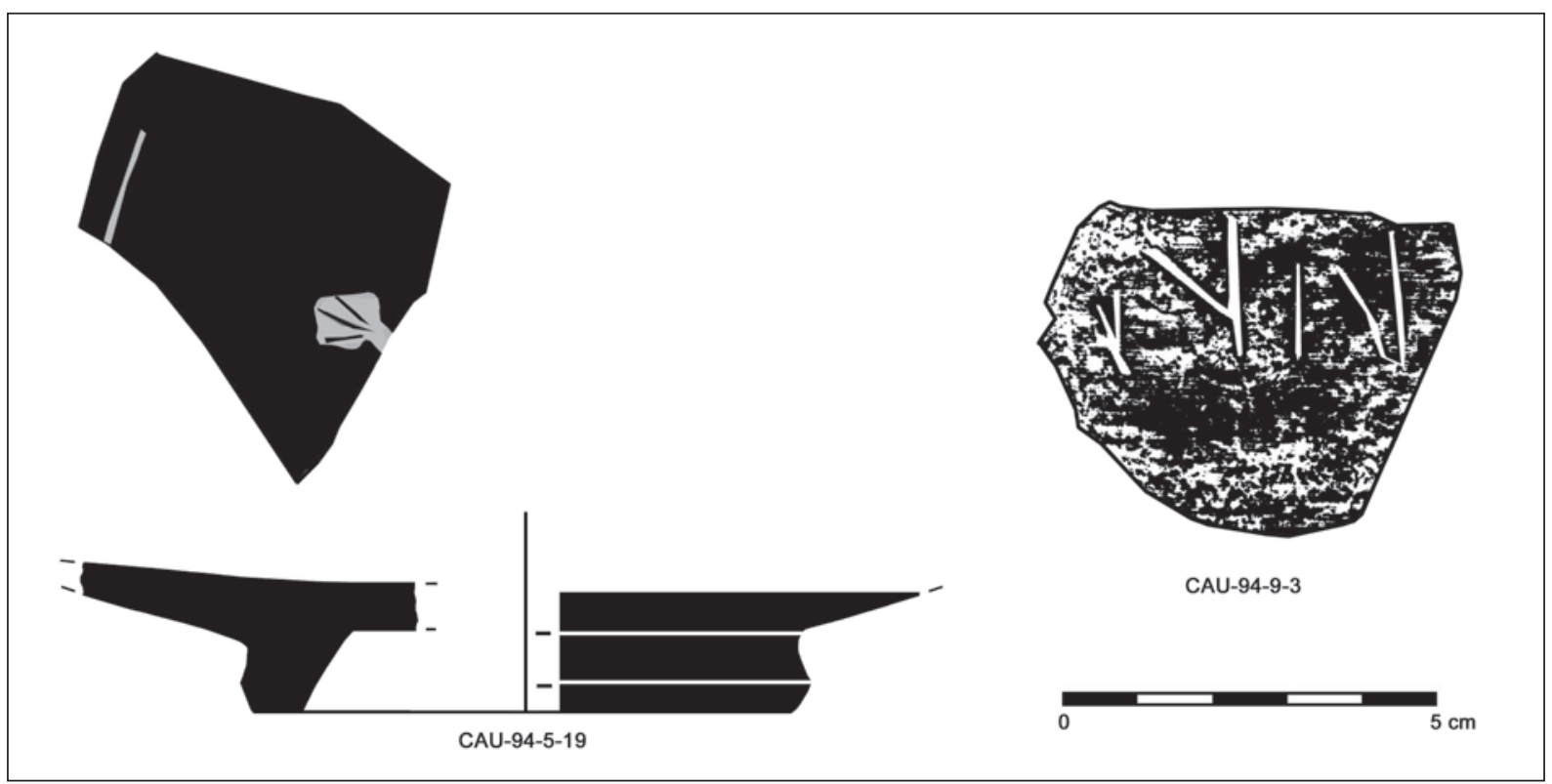

Figura 15. Cerámica Campaniense B (de Cales). Motivo losángico sobre patera y grafito en el exterior del pie de una forma L1.

También contamos con un grafito en el exterior de otro trozo de base, en este caso probablemente de una forma L.1. Este ejemplar (CAU-94-9-3) se decoró al interior con círculos concéntricos acanalados. La marca está compuesta por tres letras griegas, esgrafiadas sobre la superficie barnizada (fig. 15).

Finalmente, también incluimos en este apartado cinco fragmentos con barniz de gran calidad, semejante al B "clásico"; tanto que uno de ellos, de forma no identificable por su pequeño tamaño, podría ser de una pieza de Campaniense B muy erosionada. Se trata de trozos de base, borde y galbo de L.1, L.1 o L.8, L.5 y de otra pátera indeterminada.

\subsubsection{Otras campanienses del "Círculo de B"}

Incluimos en este último apartado los datos de los siguientes fragmentos de otras producciones cerámicas con características técnicas similares (fig. 16):

- Tres fragmentos de base, de las formas L.5 o L.7, de la Montagna Pasquinucci-127, y de una pequeña forma cerrada, posiblemente jarrita o ungüentario. 
Presentamos dibujo de la pieza mejor identificada, la que lleva la sigla CAU-94-19-3.

- Cuatro fragmentos que consideramos "indeterminados", ya que por su tamaño y mal estado de conservación no se pueden catalogar adecuadamente.

\subsubsection{Campaniense $\mathrm{C}$}

Contamos con un único fragmento (fig. 17). Esta producción, cuyo origen estaba en talleres de Sicilia, estuvo en el mercado durante los siglos II y I a.C, pero llegó en muy pocas cantidades a la península ibérica (Beltrán 1990; Sanmartí 1981: 176; Ventura 1985 y 2001: 335-337). La pieza se halló en E-XX, en concreto en el nivel artificial N-13. Se trata de un pequeño trozo de borde de una pátera Lamboglia 5, siglado como CAU-94-13-8.

A pesar de proceder de un estrato de época contemporánea, este fragmento permite añadir el nombre Caura a la lista de lugares con hallazgos de Campaniense $\mathrm{C}$, relación que incluye emporios como Gades, Onuba o Hispalis, así como otros de entidad similar a la suya como los cercanos de Italica y Orippo (Ventura 1985), además de otras localidades costeras del Algarve como Castro Marim, Tavira, Faro, Rocha Branca, Foz do Arade, Lagos o Silves (Luís 2003: 24-25 y figs. 1-4).

\subsection{Las otras producciones occidentales de barniz negro}

A finales del período helenístico surgen cerámicas que, a grandes rasgos, desarrollan una apariencia cromática común, con pastas grises, producto de una cocción reductora, y barniz negro. Sus formas están inspiradas o hechas a imitación del repertorio de las cerámicas itálicas. El análisis más detallado de los especímenes va revelando diferencias que apuntan a talleres diversos. Estos no han sido identificados aún; sin

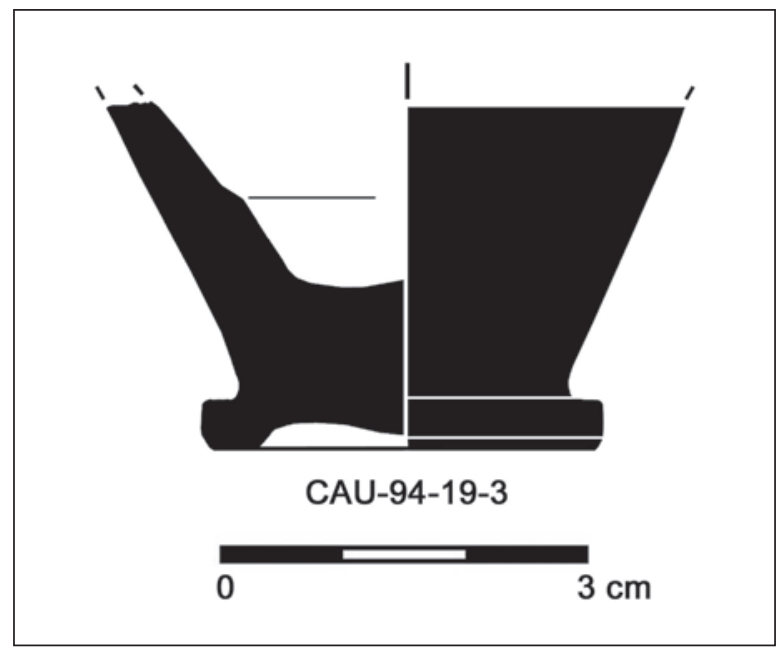

Figura 16. Otras cerámicas del Círculo de la Campaniense B.

embargo, y según los especialistas, podrían ubicarse en el Valle del Guadalquivir y la costa gaditana. Desde esta zona, sus productos se distribuirían por el occidente andaluz y, sobre todo, por las costas del Golfo de Cádiz y área del estrecho de Gibraltar, tanto en la península ibérica como en la zona norteafricana, aprovechando los circuitos del comercio marítimo (Ventura 1985; 2000: 185-186; Niveau de Villedary 2004; Principal 2009: 138). En los territorios portugueses a estas cerámicas se las conoce como campanienses de pasta cinzenta (Luís 2003: 23-38, 42-43 y fig. 3).

Entre los materiales hallados en el Corte-A no existen productos de imitación de la zona, como las cerámicas de pasta gris decoradas con emblema losángico; y ello a pesar de que Caura se encuentra en el denominado "espacio periférico de imitaciones" de la Hispania Ulterior (Principal 2009), y de que esos materiales han sido identificados en otros yacimientos del entorno próximo como Orippo e Italica (Ventura 1985: 127131). Este hecho obliga a no descartar su hallazgo en futuras excavaciones.

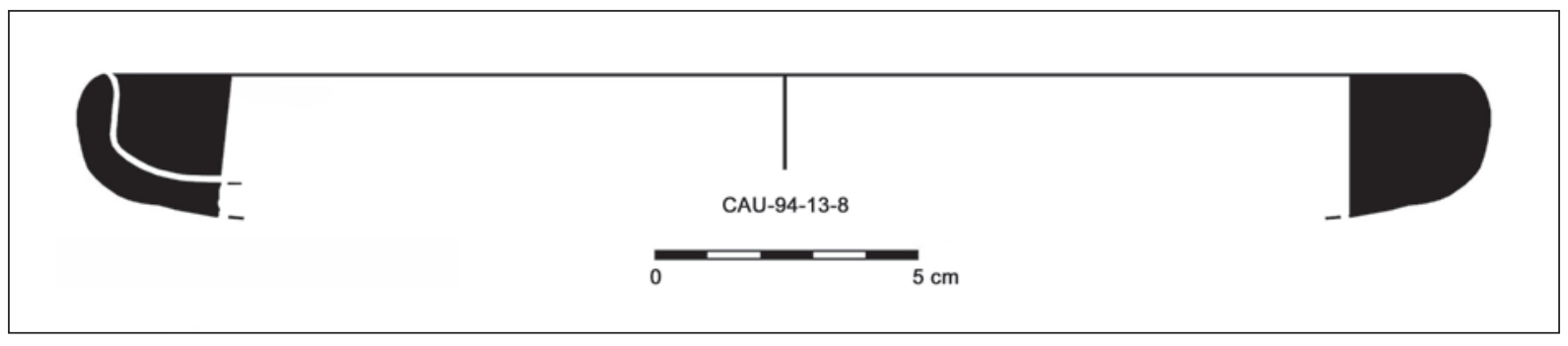

Figura 17. Cerámica Campaniense C. 


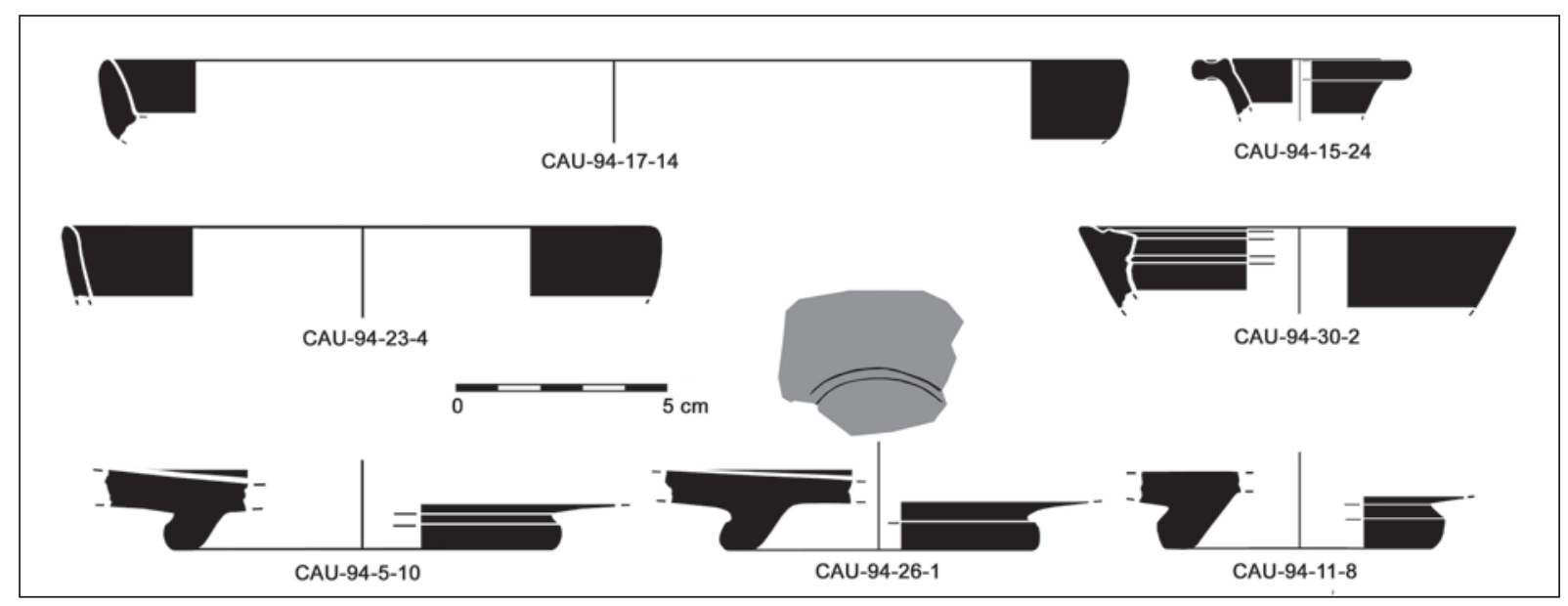

Figura 18. Producciones occidentales.

Contamos con un conjunto de 18 fragmentos, procedentes del pozo medieval (E-30) y de los estratos EXVII, E-XIX y E-XX, estos tres últimos formados en época contemporánea. Tales contextos impiden una valoración de sus ámbitos de uso original y de su cronología primaria. No obstante, su estudio permite identificar diversas producciones agrupadas conforme al criterio de pasta y barniz, ya que, dadas las características del conjunto, no podemos contar con criterios bien definidos en cuanto a tipología o decoración:

I. Pasta gris, con barniz negro mate, poco consistente.

II. Pasta gris y barniz negro de "tipo B".

III. Pasta gris, con mucha mica, y barniz negruzco y deficiente.

IV. Pasta grisácea, con barniz negro-negruzco poco consistente.

V. Pasta gris homogénea, con barniz de "tipo C".

VI. Pasta clara, beige-grisácea, con barniz negro mate.

La alta fragmentación y los efectos de la erosión impiden asignar forma concreta al $44 \%$ de la muestra (8 piezas). Los demás trozos son pies, bases y bordes. Las formas que hemos podido identificar se corresponden con recipientes abiertos -páteras (indeterminadas y L.7), cuencos (imitación de L.1) y copas (una posible L.2)-, con formas cerradas (una jarrita que tal vez imita a L.59), y con una lucerna, quizás inspirada en la tradición helenística de las lámparas de cazoleta abierta (fig. 18). Por lo que respecta a la decoración, sólo dos fragmentos de pátera presentan restos de círculos acanalados concéntricos. Finalmente, merece la pena reseñar que uno de los fragmentos tiene la peculiaridad de haber pertenecido a una forma con pie divergente (CAU-94-26-1).

\section{CONCLUSIONES}

Caura importa las principales variedades de vajilla fina de barniz negro desde el siglo V hasta el I a.C. Se incluyen aquí tanto las producciones áticas como las itálicas; también la fabricada en talleres occidentales que, entre los siglos III y I a.C., se inspiran en ambas para la elaboración de las propias (cuadro 3). Estas importaciones, junto con la actividad comercial que evidencian los restos de ánforas documentados en el registro arqueológico (Ferrer et al. 2010: 80), apuntan a una larga etapa de prosperidad local, en la que el comercio marítimo y la actividad portuaria alcanzaron un importante desarrollo.

Dadas las características de los conjuntos estudiados, su valoración numérica sólo indica ciertas tendencias, que se refieren exclusivamente a las importaciones y al consumo de vajilla de cerámica fina en la ciudad. Se trata, en cualquier caso, de conclusiones que podrán ser reforzadas o matizadas en intervenciones arqueológicas futuras.

Por lo que respecta a los siglos V y IV a.C., la cerámica de barniz negro procede de Grecia (Ática); se trataría siempre de un volumen moderado de importaciones. Entre los siglos III y II a.C., al caer las exportaciones griegas e ir escaseando esta vajilla, los vasos finos se producen en la región, como también ocurre con los de tipo Kuass por ejemplo. De todas formas, paralelamente comienzan a importarse productos del $\mathrm{Me}$ diterráneo central, en concreto desde talleres itálicos. Algunos de estos elementos exóticos son de muy alta calidad, como la cerámica de Cales. Finalmente, entre los siglos II y I a.C. se constata un notable incremento de las importaciones. Si la tendencia observada en la 
Cuadro 3. Corte-A de Caura. Cerámica fina de barniz negro de los siglos V-I a.C.

\begin{tabular}{|c|c|c|c|}
\hline Importaciones & Productos occidentales & Fragmentos & Datación \\
\hline Griega (Ática) & & 52 & siglos V-IV a.C. \\
\hline Itálica (de Cales) & & 2 & siglos III-II a.C. \\
\hline Itálica (Campania/Toscana/Sicilia) & & 173 & siglos II-I a.C. \\
\hline & Producciones diversas & 18 & siglos II-I a.C. \\
\hline
\end{tabular}

excavación de 1994 se confirmara en actuaciones futuras con contextos estratigráficos menos alterados, podría concluirse que la llegada a Caura de recipientes finos de barniz negro triplicó ampliamente el volumen de importaciones griegas de los momentos precedentes. Estos productos más recientes se habrían mantenido en el mercado y en los hogares de la ciudad hasta que el cambio en los gustos acabó poniendo de moda los barnices rojos (terra sigillata) y desplazando a los negros. En nuestro caso, se trataba fundamentalmente de importaciones procedentes de Italia central (Campania), sobre todo del entorno de Cales. Esto no impidió la presencia también de algunos otros elementos cerámicos oriundos de Sicilia (Campaniense C). Por su parte, los productos occidentales mantendrían su cuota de mercado, aunque con una mayor diversificación de producciones y/o talleres, cuestión evidenciada en la variedad de pastas y de tipos de barnices presentes en el conjunto aquí estudiado.

\section{Agradecimientos}

Este trabajo se ha elaborado en el marco del Grupo HUM-949 del III Plan Andaluz de Investigación.

\section{BIBLIOGRAFÍA}

Abad, L. (1983): "Un conjunto de materiales de La Serreta de Alcoy". Lvcentvm 2: 173-197.

Arteaga, O.; Schulz, H.D. y Roos, A.M. (1995): “El problema del 'Lacus Ligustinus'. Investigaciones geoarqueológicas en torno a las Marismas del Bajo Guadalquivir", en Tartessos 25 años después, 1968-1993, Jerez de la Frontera: 99-135. Jerez de la Frontera, Ayuntamiento de Jerez de la Frontera.

Aubet, M.E.; Serna, M.R.; Escacena, J.L. y Ruiz Delgado, M.M. (1983): La Mesa de Setefilla. Lora del Río (Sevilla). Campaña de 1979. Excavaciones
Arqueológicas en España 122. Madrid, Ministerio de Cultura.

Bats, M. (1988): "Vaisselle et alimentation à Olbia de Provence (v.350-v.50 av. J.C.). Modèles culturels et catégories céramiques". Revue Archaéologique de Narbonnaise 18, supplément: 5-72.

Belén, M. (1993): "Mil años de historia de Coria: la ciudad prerromana", en J.L. Escacena (coord.), Arqueología de Coria del Río y su entorno, Azotea 1112 (Monográfico de la Revista de Cultura del Ayuntamiento de Coria del Río): 35-60.

Belén, M. y Escacena, J.L. (1992): “Las necrópolis ibéricas de Andalucía occidental”, en J. Blánquez y V. Antona (coords.), Congreso de arqueología ibérica. Las necrópolis (Serie Varia 1): 509-529. Madrid, Universidad Autónoma de Madrid.

Beltrán, M. (1990): Guía de la Cerámica Romana. Zaragoza, Pórtico.

Borja, F. (2013): "La desembocadura del Guadalquivir en la segunda mitad del Holoceno", en L. García Sanjuán et al. (eds.), El asentamiento prehistórico de Valencina de la Concepción (Sevilla): Investigación y tutela en el 150 aniversario del descubrimiento de La Pastora: 93-112. Sevilla, Universidad de Sevilla.

Caballos, A.; Escacena, J.L. y Chaves, F. (2005): Arqueología en Laelia (Cerro de la Cabeza, Olivares, Sevilla). Spal Monografías VI. Sevilla, Universidad de Sevilla.

Cabrera, P. (1994): “Cádiz y el comercio de productos griegos en Andalucía occidental durante los siglos V y IV a.C.". Trabajos de Prehistoria 51 (2): 89-101.

Cabrera, P. (1997): "La presencia griega en Andalucía, siglos VI al IV a.C.”, en J. Fernández Jurado et al. (eds.), La Andalucía ibero-turdetana (siglos VI-IV a.C.), Huelva Arqueológica XIV: 367-390.

Coto, M. (2011): "Resucitando identidades perdidas: problemas en torno a la cerámica turdetana". Estract Crític 5 (II): 293-304. 
Díes, E. (2001): "La influencia de la arquitectura fenicia en las arquitecturas indígenas de la Península Ibérica (s. VIII-VII)", en D. Ruiz Mata y S. Celestino (eds.), Arquitectura oriental y orientalizante en la Península Ibérica: 69-121. Madrid, Centro de Estudios del Próximo Oriente - Consejo Superior de Investigaciones Científicas.

Escacena, J.L. (2002): “Dioses, toros y altares. Un templo para Baal en la antigua desembocadura del Guadalquivir", en E. Ferrer (ed.), Ex Oriente Lux: Las religiones orientales antiguas en la Península Ibérica: 33-75. Sevilla, Universidad de Sevilla.

Escacena, J.L. y Belén, M. (1994): “Sobre las necrópolis turdetanas”, en P. Sáez y S. Ordóñez (eds.), Homenaje al profesor Presedo: 237-265. Sevilla, Universidad de Sevilla.

Escacena, J.L.; Belén, M.; Beltrán, J.; Pardo, M.R, y Ventura, J.J. (1997): "Proyecto Estuario. Actuaciones de 1993". Anuario Arqueológico de Andalucía / 1993. II, Actividades Sistemáticas: 142-148. Sevilla, Consejería de Cultura de la Junta de Andalucía.

Escacena, J.L.; Feliu, M.J. e Izquierdo, R. (2010): “El Cerro de la Albina y la metalurgia de la plata en Tartessos". De Re Metallica 14: 35-51.

Escacena, J.L. e Izquierdo, R. (1999): "Proyecto Estuario. Intervención Arqueológica de 1994". Anuario Arqueológico de Andalucía / 1994. II, Actividades Sistemáticas: 161-166. Sevilla, Consejería de Cultura de la Junta de Andalucía.

Escacena, J.L. e Izquierdo, R. (2000): “Altares para Baal". Arys 3: 11-40.

Escacena, J.L. e Izquierdo, R. (2001): “Oriente en Occidente. Arquitectura civil y religiosa en un barrio fenicio de la Caura tartésica", en D. Ruiz Mata y S. Celestino (eds.): Arquitectura Oriental y Orientalizante en la Península Ibérica: 123-157. Madrid, Centro de Estudios del Próximo Oriente-Consejo Superior de Investigaciones Científicas.

Escacena, J.L. e Izquierdo, R. (2008): “A propósito del paisaje sagrado fenicio de la paleodesembocadura del Guadalquivir", en X. Dupré et al. (eds.), Saturnia Tellus. Definizioni dello spazio consacrato in ambiente etrusco, italico, fenicio-punico, iberico e celtico: 431-455. Roma, Consiglio Nazionale delle Ricerche.

Escacena, J.L. y Moreno, V. (2014): “Cerámica de tipo Kuass procedente de Caura. ¿Testimonios de un nuevo centro de producción?. Archivo Español de Arqueología 87 (en prensa).

Escacena, J.L. y Henares, M.T. (1999): “Un fondo de cabaña de época tartésica en La Puebla del Río
(Sevilla). Intervención Arqueológica de Urgencia". Anuario Arqueológico de Andalucía / 1994. III, Actividades de Urgencia: 504-510. Sevilla, Junta de Andalucía.

Fernández Gómez, F. y De la Hoz, A. (1993): “Excavaciones en la necrópolis romana". Azotea 11-12: 107-118.

Fernández Jurado, J. (1985): La presencia griega arcaica en Huelva (Monografías Arqueológicas. Colección Excavaciones en Huelva 1/1984). Huelva, Diputación Provincial de Huelva.

Ferrer, E.; García Fernández, F.J. y Escacena, J.L. (2010): "El tráfico comercial de productos púnicos en el antiguo estuario del Guadalquivir". Mainake XXXII (I): 61-89.

Gavala, J. (1959): La geología de la costa y bahía de Cádiz y el poema "Ora Maritima”, de Avieno. Instituto Geológico y Minero de España, Madrid. (Ed. facsímil en Cádiz, Diputación Provincial de Cádiz, 1992).

Harris, E.C. (1991): Principios de estratigrafía arqueológica. Barcelona, Crítica.

Henares, M.T. (2011): “Actividad arqueológica de urgencia: sondeos auscultatorios en el colegio público «Cerro de San Juan» de Coria del Río (Sevilla)". Anuario Arqueológico de Andalucía / 2011 (e.p.). Sevilla, Junta de Andalucía.

Jiménez, A. (2002): "Excavación en c/ Abades 41-43 (Sevilla); del siglo III a.C. al siglo IV". Romula 1: 125-150.

Keay, S.J.; Wheatley, D. y Poppy, S. (2001): “The territory of Carmona during the Turdetanian and Roman periods: some preliminary notes about visibility and urban location", en A. Caballos (ed.), Carmona Romana. Actas del II Congreso de Historia de Carmona: 397-412. Carmona, Ayuntamiento de Carmona - Universidad de Sevilla.

Lamboglia, N. (1952): "Per una clasificacione preliminare della ceramica campana", en Atti del I Congresso Internazionale di Studi Liguri: 139-206. Bordighera.

Luís, L. (2003): As cerâmicas campanienses de Mértola. Trabalhos de Arqueologia 27. Lisboa, Instituto Português de Arqueologia.

Menanteau, L. (1982): Les marismas du Guadalquivir, exemple de transformation d'un paysage alluvial au cours du Quaternaire récent. París, Université de Paris-Sorbonne.

Morel, J.-P. (1981): La céramique campanienne. Les formes. Écoles Françaises d'Athenes et de Rome, Bibliothèque, fasc. 244. París. 
Muñoz, A. (1988): “Avance sobre el estudio de los ungüentarios helenísticos de Cádiz, 1986". Anuario Arqueológico de Andalucía / 1986: 520-525. Sevilla, Junta de Andalucía.

Niveau de Villedary, A.M. (2004): "Evidencias de la producción de cerámicas barnizadas "tipo Kuass" en la Bahía de Cádiz”, en Las industrias alfareras y conserveras fenicio-púnicas de la Bahía de Cádiz: 171-195. Córdoba, Cajasur.

Niveau de Villedary, A.M. (2009): "La cerámica «Tipo Kuass»", en D. Bernal y A. Ribera (eds.), Cerámicas hispanorromanas. Un estado de la cuestión: 245-262. Cádiz, Universidad de Cádiz.

Padilla, A. (1993): "Caura: el topónimo", en J.L. Escacena (coord.), Arqueología de Coria del Río y su entorno, Azotea 11-12 (Monográfico de la Revista de Cultura del Ayuntamiento de Coria del Río): 63-64.

Pérez, J. (2009): "La cerámica de barniz negro", en D. Bernal y A. Ribera (eds.), Cerámicas hispanorromanas. Un estado de la cuestión: 263-274. Cádiz, Universidad de Cádiz.

Principal, J. (2009): “El Mediterráneo occidental como espacio periférico de imitaciones", en D. Bernal y A. Ribera (eds.), Cerámicas hispanorromanas. Un estado de la cuestión: 127-143. Cádiz, Universidad de Cádiz.
Rouillard, P. (1975): "Coupes attiques à figures du IV s. en Andalousie". Mélanges de la Casa de Velázquez 11: 21-49.

Sánchez Fernández, C. (1992): "Las copas tipo Cástulo en la Península Ibérica". Trabajos de Prehistoria 49: 327-333.

Sanmartí, E. (1981): “Las cerámicas de barniz negro y su función delimitadora de los horizontes ibéricos tardíos (s. III-I a.C)", en La baja época de la cultura ibérica: 163-179. Madrid, Asociación Española de Amigos de la Arqueología.

Sparkes, B.A. y Talcott, L. (1970): Black and plain pottery of the $6^{\text {th }}, 5^{\text {th }}$ and $4^{\text {th }}$ centuries B.C. The Athenian Agora, XII. Princeton, American School of Classical Studies at Athens.

Ventura, J.J. (1985): “La cerámica campaniense «C»y seudocampaniense de pasta gris en la provincia de Sevilla". Lvcentvm 4: 125-132.

Ventura, J.J. (1990): La cerámica campaniense en Andalucía occidental. Tesis Doctoral, Universidad de Sevilla. Inédita

Ventura, J.J. (2001): “Cerámicas de barniz negro en Carmona", en A. Caballos (ed.), Carmona Romana: 321-337. Carmona, Universidad de Sevilla - Ayuntamiento de Carmona. 